\title{
What is the Cost of Sadness? Age Differences in Risky Medical Decision Making
}

Jenna M. Wilson

West Virginia University, jw0097@mix.wvu.edu

Follow this and additional works at: https://researchrepository.wvu.edu/etd

Part of the Developmental Psychology Commons

\section{Recommended Citation}

Wilson, Jenna M., "What is the Cost of Sadness? Age Differences in Risky Medical Decision Making" (2021). Graduate Theses, Dissertations, and Problem Reports. 8083.

https://researchrepository.wvu.edu/etd/8083

This Dissertation is protected by copyright and/or related rights. It has been brought to you by the The Research Repository @ WVU with permission from the rights-holder(s). You are free to use this Dissertation in any way that is permitted by the copyright and related rights legislation that applies to your use. For other uses you must obtain permission from the rights-holder(s) directly, unless additional rights are indicated by a Creative Commons license in the record and/ or on the work itself. This Dissertation has been accepted for inclusion in WVU Graduate Theses, Dissertations, and Problem Reports collection by an authorized administrator of The Research Repository @ WVU.

For more information, please contact researchrepository@mail.wvu.edu. 
Graduate Theses, Dissertations, and Problem Reports

2021

What is the Cost of Sadness? Age Differences in Risky Medical Decision Making

Jenna M. Wilson

Follow this and additional works at: https://researchrepository.wvu.edu/etd

Part of the Developmental Psychology Commons 
What is the Cost of Sadness? Age Differences in Risky Medical Decision Making Jenna M. Wilson, M.S

\author{
Dissertation submitted to the \\ Eberly College of Arts and Sciences \\ at West Virginia University \\ in partial fulfillment of the requirements \\ for the degree of \\ Doctor of Philosophy \\ in \\ Life-Span Developmental Psychology \\ JoNell Strough, Ph.D., Chair \\ Natalie J. Shook, Ph.D. \\ Amy Gentlzer, Ph.D. \\ Caroline Groth, Ph.D.

\begin{abstract}
Department of Psychology Morgantown, West Virginia
\end{abstract} \\ 2021
}

Keywords: medical decision making, risk taking, sadness, aging Copyright 2021 Jenna Wilson 


\begin{abstract}
What is the Cost of Sadness? Age Differences in Risky Medical Decision Making
\end{abstract}

\title{
Jenna Wilson
}

It's unknown how a sadness induction affects risky decision making within the medical domain, as well as whether the cognitive appraisal tendencies of uncertainty and situational control, which are theorized to underlie sadness, explain why sadness is related to subsequent decision making. Additionally, although initial work suggests that age differences in risky decision making may not exist within the medical domain, this limited work has only used one measure of risky medical decision making (e.g., Butler et al., 2012; Hanoch et al., 2018; Rosman et al., 2013). The first aim of the current study was to examine the effect of a sadness induction on risky medical decision making, and to explore whether the appraisal tendencies of uncertainty and situational control explained the link between sadness and decision making. The second aim of the current study was to examine the association between age and risky medical decision making utilizing a different measure of medical risk taking than has been used previously. The third aim of the current study was to explore whether age moderated the association between the sad video condition and risky medical decision making, as well as the association between the sad video condition and appraisals of situational control. Younger (aged 18-35) and older (aged 60-89) adults from the U.S. ( $N=270 ; 51.5 \%$ female; $77 \%$ White) were recruited online via CloudResearch. Participants were randomly assigned to either a sad condition or neutral control condition and watched a short video clip. Participants then read three hypothetical medical decision scenarios that described being diagnosed with either cancer, a stroke, or an ankle fracture. After each scenario, participants were presented with two treatment options - Treatment A was lower risk and Treatment B was higher risk. For each decision scenario, participants rated their likelihood to choose Treatment A relative to Treatment B, as well as answered questions about their appraisals of uncertainty and situational control related to the treatment outcomes. Older adults were less likely to choose the riskier treatment option (Treatment B) than younger adults. However, this finding was no longer significant after accounting for age differences in baseline negative affect, such that older adults reported less negative affect at baseline than younger adults. The sad video induction, compared to the neutral control condition, did not have a significant effect on risky medical decisions, but an exploratory analysis showed that baseline sadness was related to greater risky medical decision making. However, the appraisal tendencies did not statistically account for why baseline sadness was related to risky medical decisions. Additionally, age moderated the association between the sad video condition and appraisals of situational control, such that older adults in the sad condition reported higher appraisals of situational control than older adults in the neutral condition. Together, the findings suggest that baseline sadness is related to greater risk taking, but it's unclear why since the appraisals tendencies did not explain this association. Moreover, age is not related to risky medical decision making after accounting for age differences in affect. 


\section{ACKNOWLEDGMENTS}

Throughout the writing of this dissertation I have received a great deal of support and assistance. This research was made possible by the Eberly College of Arts and Sciences and the Department of Psychology. I would like to thank Dr. JoNell Strough, my dissertation chair and advisor, for her mentorship and guidance throughout this project. I would also like to thank my committee members, Drs. Natalie Shook, Amy Gentzler, and Caroline Groth, for their feedback and time. In addition, I would like to thank my colleagues for all of their support. Lastly, I am incredibly grateful for the endless support and encouragement I have received from my family and friends throughout my graduate career. 
Table of Contents

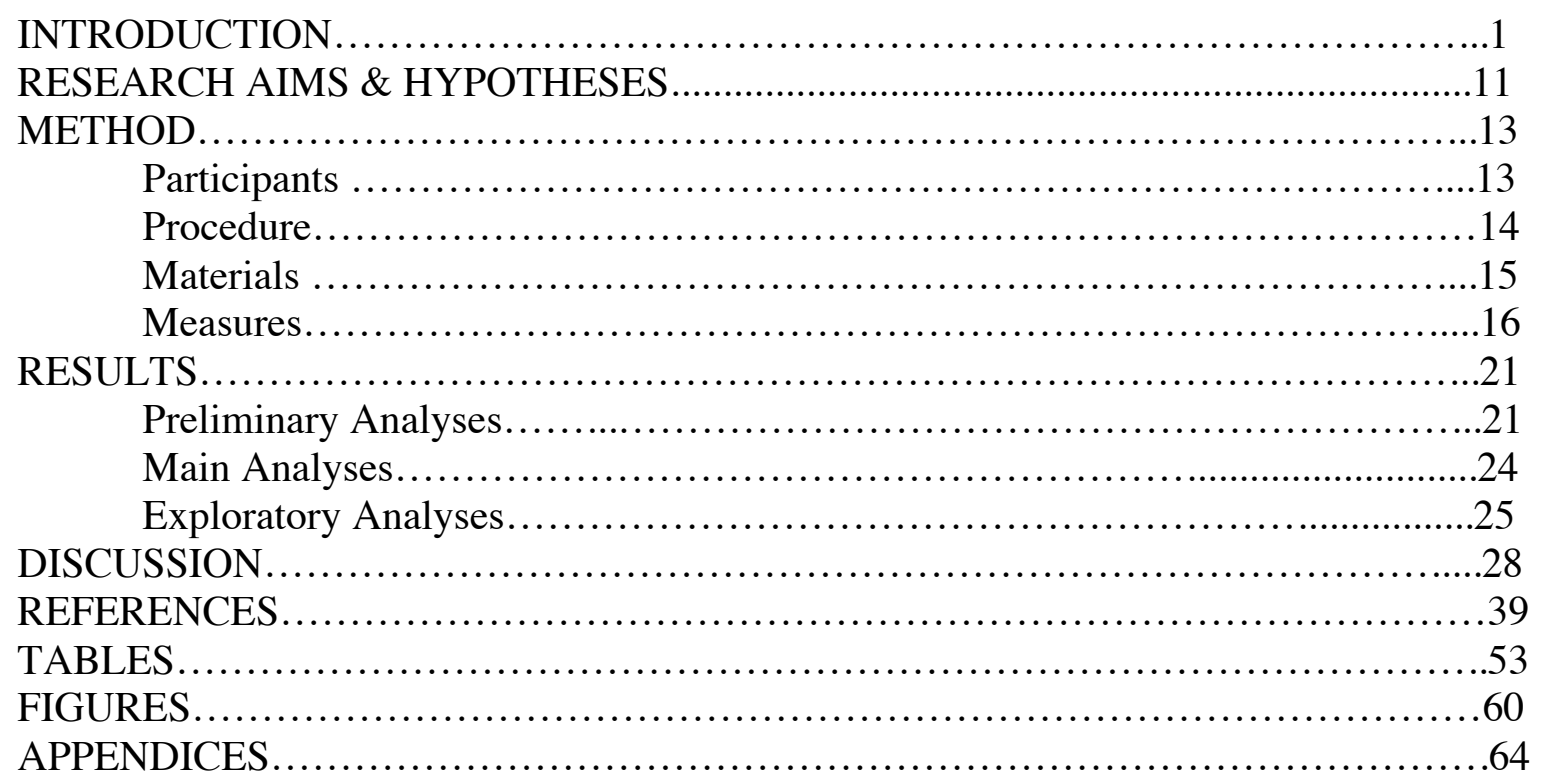


What is the Cost of Sadness? Age Differences in Risky Medical Decision Making The diagnosis of a serious illness or injury, possibly incurable, causes people to make high-stake medical decisions while often feeling powerless and uncertain (Ellis et al., 2019). Although sadness has been posited to be an emotion of particular relevance in the domain of risky medical decision making (Derry et al., 2019), empirical work has not yet tested the effect of sadness on risky medical decisions. Further, theory argues that sadness is characterized by cognitive appraisal tendencies of uncertainty and situational control, which subsequently lead to decisions that are in line with the appraisal tendencies (Lerner \& Keltner, 2000). But, whether these appraisal tendencies explain the association between sadness and risky decision making has yet to be tested. The first aim of the current study was to examine the effect of a sadness induction on risky medical decision making, and to explore whether the appraisal tendencies of uncertainty and situational control explained the link between sadness and decision making. Additionally, as the population age continues to increase (He et al., 2015), and those older in age typically face more medical decisions than those younger in age (Leventhal et al., 2015), it is critical to understand how age is associated with risky medical decision making. Although some research suggests that there may not be age differences in the domain of medical decision making (e.g., Butler et al., 2012; Hanoch et al., 2018), this research is limited. The second aim of the current study was to examine the association between age and risky medical decision making. Further, theory suggests that sadness is a highly salient emotion among older relative to younger adults (Kunzmann et al., 2014). Initial empirical work showed that older adults were less risk taking than younger adults after a sadness induction (Chou et al., 2007), which suggests that age may moderate the association between sadness and risky decision making. Additionally, there tends to be a higher prevalence of declines across domains (e.g., 
health) in older adulthood compared to younger adulthood, which has been posited to result in lower personal control among older adults (Kunzmann et al., 2014). Thus, age may also moderate the association between sadness and appraisals of situational control. Therefore, the third aim of the current study was to explore whether age moderated the association between the sad video condition and risky medical decision making, as well as the association between the sad video condition and appraisals of situational control.

\section{Affect and Risky Medical Decisions}

Decisions related to health are common across adulthood and often have consequential impacts on the quality and trajectory of well-being (Carpenter \& Niedenthal, 2018). Many medical decisions involve high-stakes, such as those related to the diagnosis and treatment of an illness or injury. While there has been an increasing emphasis on patient autonomy within the U.S. healthcare system (Botti \& Iyengar, 2006), patients and their families often lack sufficient medical knowledge and experience, which makes them vulnerable to making uninformed predictions or having unrealistic expectations about the outcomes of a treatment (Ferrer \& Ellis, 2019). Further, many medical choices are complex and involve high levels of uncertainty, thus posing more of a challenge to patients (Ellis et al., 2018; Ferrer \& Ellis, 2019). Due to the complexity in medical decision making, it is critical to examine what factors may influence these decisions.

Medical decisions tend to have an affective component, such that people rarely make these decisions in the absence of emotion (Ferrer \& Mendes, 2018). More commonly, these decisions are made in negative affective states after receiving unpleasant and distressing news related to a diagnosis or presentation of treatment options (Ferrer \& Mendes, 2018). Sadness is one of the most commonly experienced negative emotions (Bryant \& Zillman, 1984; Lerner \& 
Tiedens, 2006) and has been acknowledged as a particularly relevant emotion in the domain of medical decision making (Derry et al., 2019; Edlund \& Sneed, 1989). Researchers argue that sadness is a 'normal' or natural response when reacting to discouraging life events, such as the diagnosis of a medical condition (Lokko \& Stern, 2014).

Moreover, trying to understand the risks and benefits of medical decisions can be emotional for the decision maker, ultimately resulting in altered and biased perceptions (Zikmund-Fisher et al., 2010). This is important to consider because these negative affective states may overly impact a patient's treatment decision, and consequently result in later regret (Ferrer \& Ellis, 2019). Understanding the implications of how emotional states, such as sadness, influence medical decisions can inform healthcare policies. For example, medical decisions can be guided under a decision architecture that considers a patient's emotional state (Ferrer et al., 2016), and thus, tailors discussions about treatment options accordingly.

Theoretical framework. Within the field of decision science, considering the relation between specific, or discrete, emotions and decisions is relatively recent. The appraisal tendency framework (Lerner \& Keltner, 2000, 2001) posits that there are central cognitive appraisal dimensions that underlie an emotion and result in an implicit predisposition to judge subsequent situations in line with the cognitive appraisals that characterize that emotion (Lerner \& Tiedens, 2006). For example, an individual may experience sadness after being diagnosed with cancer, and consequently, the appraisal tendencies activated by sadness will carry over and influence subsequent decisions.

Smith and Ellsworth (1985) provided the groundwork for emotions and appraisal dimensions by conducting a study that looked at how 15 different emotions mapped onto six appraisal dimensions by running Symmetric Individual Differences Multidimensional Scaling 
(SINDSCAL). They showed that sadness is an emotion that is characterized by high appraisals of situational control, a sense that outcomes are based on factors beyond individual control (e.g., fate), and uncertainty due to the perception that negative events are unpredictable (Smith \& Ellsworth, 1985). Thus, theoretically, after a sadness induction, an individual will make subsequent decisions while experiencing high levels of uncertainty and situational control, and these appraisal tendencies should explain the link between sadness and the decisions made.

Empirical work exploring the effects of sadness on decision making is limited and suggests that sadness is related to less risk-taking behavior (e.g., Cryder et al., 2008; Lerner et al., 2013). However, and the majority of this research has focused on financial decisions. One study showed that young adults induced to feel sad were less risk taking when making lottery choices than those in a neutral condition (Treffers et al., 2012). Similarly, another study found that young adults induced to feel sad showed less risk taking on the Balloon Analogue Risk Task (BART), which involves earning hypothetical tokens, than those induced to feel angry (Szasz et al., 2016). Young adults induced to feel sad were also less risk taking when presented with hypothetical life dilemmas relative to those in neutral and happy conditions (Chou et al., 2007). Despite the real-world relevance of how sadness may affect risky medical decisions, this remains an area largely understudied.

Based on prior research conducted in other decision domains, it follows that sadness should be related to less risky medical decision making. Therefore, when presented with a higher risk medical treatment option versus a lower risk treatment option, an individual who is in a sad condition should be more likely to choose the lower risk treatment compared to an individual in a neutral condition. Additionally, the appraisal tendency framework posits that an individual induced to feel sad should judge subsequent situations and decisions in line with the cognitive 
appraisals that underlie sadness (Lerner \& Keltner, 2000). Yet, empirical work testing this proposition are scarce. Thus, it remains unknown whether the appraisal dimensions that underlie sadness account for why those who are induced to feel sad tend to show less risk-taking tendencies. Theoretically, appraisal tendencies should explain the association between sadness and decision making, such that higher appraisals of situational control and uncertainty for those in the sad condition should be related to less risky medical decision making.

\section{Age and Risky Medical Decisions}

There is an abundance of research showing age differences in decision making when comparing younger and older adults (see Hess et al., 2015; Strough et al., 2020 for reviews). Medical decisions often increase with age and some have shown that older adults report more health-related problems than younger adults (Folkman et al., 1987; Hershey et al., 2015). Medical decisions may also be more challenging and consequential for older adults than younger adults due to physical and cognitive declines that occur with aging, as well as less time remaining in life to recover from poor decisions (Agarwal et al., 2009).

A large body of research shows that older adults tend to be less risk taking relative to younger adults (Josef et al., 2016; Mamerow et al., 2016; Mata et al., 2016), however, some studies show that they are equally or more risk taking (Chou et al., 2007; Mather et al., 2012). Inconsistent patterns within the literature may be due to the varying types of risk measures (e.g., self-report versus behavioral; see Mata et al., 2018, for a review) as well as the domain that risk taking is assessed (e.g., financial, health/safety, medical). Prior work has shown that older adults tend to be less risk taking than younger adults for decisions related to health and safety, such as eating foods high in cholesterol and driving a car without a seatbelt (Bonem et al., 2015; Rolison 
et al., 2014; Shook et al., 2019). However, little research has investigated age differences in risky decisions in the medical domain.

The majority of work on age and risky medical decision making has used the medical subscale of the Domain-Specific Risk-Taking scale (DOSPERT, Blais \& Weber, 2006). Butler et al. (2012) developed the medical subscale which includes decisions about donating a kidney to a stranger, giving blood, having knee surgery to relieve arthritis, receiving general anesthesia for wisdom teeth removal, taking daily medication for allergies, and participating in a clinical trial for drug effectiveness. Three studies have examined the association between age and risk taking using the medical subscale and found no age differences (e.g., Butler et al., 2012; Hanoch et al., 2018; Rosman et al., 2013). Age differences in risky decision making may depend on the domain. Although this initial evidence suggests that within the medical domain there may not be age differences, the null findings may reflect issues regarding the validity and internal consistency of the medical subscale of the DOSPERT.

Most of the items on the medical DOSPERT reflect decisions that are voluntary and do not necessarily involve high risky procedures (e.g., giving blood) (Hanoch et al., 2013). Further, some items refer to medical procedures that do not have a direct benefit to the decision maker, but rather offer benefits to others, such as donating a kidney to a stranger. Hanoch et al. (2018) showed that perceiving more benefits from the medical decision was related to a greater likelihood of engaging in risk taking. Moreover, all three studies (e.g., Butler et al., 2012; Hanoch et al., 2018; Rosman et al., 2013) that explored the association between age and risk taking using the medical DOSPERT demonstrated low internal consistency among the six items, 
with Cronbach's alphas ranging from $0.49-0.61 .{ }^{1}$ Low alphas indicate that the items of the scale might measure different things and have a small relation with each other (Corbetta, 2003).

Together, the limited research on age and risky medical decision making suggests that age differences may not exist. However, there are several of limitations with the medical subscale of the DOSPERT, and this scale also fails to assess the types of risky medical decisions that patients with critical illnesses (e.g., cancer) face. Therefore, more work investigating age differences in the domain of medical decisions using a measure that more closely captures patients' attitudes towards risky medical options is necessary (Hanoch et al., 2013).

\section{Affect, Age, and Risky Medical Decisions}

Researchers have suggested that age may moderate the effects of emotions predicted by the appraisal tendency framework and have emphasized that health-related decisions are of particular importance to explore this moderation (Ferrer et al., 2016). Indeed, there are multiple theoretical perspectives on age-related changes in emotion including the socioemotional selectivity theory (Carstensent et al., 2003) and the discrete emotions approach (Kunzmann et al., 2014). While these theories suggest that age would moderate the association between sadness and risky medical decision making, these are competing theoretical perspectives that would hypothesize opposing directions of a moderation.

Affect and age. The socioemotional selectivity theory suggests that with increasing age, there is a shift in time perspective towards the present moment, or "here and now", which affects motivational goals (Carstensen et al., 2003). This shift in time perspective is thought to explain

\footnotetext{
${ }^{1}$ In an existing dataset from the Strough/Shook lab, age was not significantly related to the medical subscale $(r=0.62, p=0.45)$. The reliability of the medical subscale was a Cronbach's alpha of 0.38. Examining the reliability per age group (i.e., younger adults aged 18-36 and older adults aged $65+$ years) showed that Cronbach's alpha was 0.38 among younger adults and 0.41 among older adults.
} 
why older adults relative to younger adults tend to prioritize positive and avoid negative experiences to maximize emotional well-being in the present moment (Carstensen, 2006; Mather, 2012). The socioemotional selectivity theory focuses on the valence of emotions (e.g., positive, negative) and suggests that older adults may demonstrate better emotion regulation of negatively valenced emotions than younger adults.

Despite an increase in health-related problems with increasing age, older adults tend to have as good, if not better, emotional experiences relative to younger adults (Carstensen et al., 2000; Carstensen et al., 2003; see Mikels et al., 2015 for a review). For example, older adults report greater positive affect and life satisfaction and lesser negative affect, anxiety, and depression compared to younger adults (Carstensen et al., 2000; Löckenhoff \& Carstensen, 2004; Mroczek \& Kolarz, 1998; Shook et al., 2017; Stone et al., 2010). According to the socioemotional selectivity theory, older adults are able to regulate their emotional reactions better than younger adults, and thus, there may be a stronger effect of sadness on younger adults' risky medical decisions than older adults' decisions. However, this theory focuses on broad positive and negative affective dimensions, which may limit the ability to apply this theory when examining age differences in the functions of specific emotions.

Recently, the discrete emotions approach has been proposed and has specifically focused on the role of sadness in the life stages of younger adulthood and older adulthood (Kunzmann et al., 2014). This theory posits that young and older adulthood are two stages in life that are differentially associated with sadness. Older age is typically associated with a higher prevalence of losses and declines across domains than in young adulthood, including losses in physical health and cognitive functioning (e.g., Lindenberger \& Baltes, 1997), as well as social losses such as the death of a friend (e.g., Palmore, 1981). Due to these losses, high appraisals of 
situational control (e.g., fate) are posited to be more accessible in older age than young adulthood because of a decline in personal control (Kunzmann et al., 2014). Therefore, it has been suggested that sadness is an emotion that is salient among older adults, and thus, older adults may show more frequent and intense levels of sadness than younger adults (Kunzmann et al., 2014).

Empirical work examining age differences in sadness is limited. In a 10-year longitudinal study of older adults (aged 64-94, $M=72.25$ years, $S D=5.81$ ), Wrosch et al. (2018) demonstrated that the intensity of self-reported sadness increased over time, but only among those who perceived low levels of control over their life. Other studies have used video clips to induce sadness and have shown mixed findings. Two studies induced sadness and found that older adults reported greater sadness than younger adults (Jenkins \& Andrews, 2012; Seider et al., 2011). Another study used two different videos to induce sadness and found that older adults relative to younger adults reported greater sadness after the video that was age-relevant (i.e., about Alzheimer's disease) but found no age differences after the other video that was considered age-neutral (i.e., about someone's father dying) (Kunzmann \& Gruhn, 2005). These findings suggest that the content of the sadness-eliciting stimuli is important to consider when examining age differences, and that it is important to use stimuli that is relevant to both age groups. According to the discrete emotions approach, sadness should be more salient and intense among older adults, and thus, there may be a stronger effect of sadness on older adults' risky medical decisions than younger adults' decisions.

Moderating effects of age. It largely remains unknown how age-related changes in emotions influence risky decision making. When comparing older adults induced to feel sad versus those in a neutral and happy condition, Chou et al. (2007) showed that those in the sad 
video condition were less risk taking on a task about hypothetical life dilemmas. Moreover, older adults in the sad video condition were also less risk taking than younger adults in the sad video condition (Chou et al., 2007). This initial evidence suggests that age may moderate the association between sadness and risky decision making. Therefore, older adults in a sad condition may report less risky medical decisions than younger adults in a sad condition.

Likewise, it is unclear how age-related changes in emotions affect appraisal tendencies. Situational control is one of the appraisal dimensions that characterizes sadness and is speculated to explain why sadness is related to less risk taking. Because older adults tend experience a decline in personal control (Kunzmann et al., 2014) due to a higher prevalence of losses in life than younger adults (Lindenberger \& Baltes, 1997), age may moderate the association between sadness and appraisals of situational control. Therefore, older adults in a sad condition may report higher appraisals of situational control than younger adults in a sad condition.

\section{Summary}

Although there are several negative emotions that a decision maker may experience after the diagnosis of a medical condition, sadness has been identified as a common emotion within the domain of medical decisions (Derrye t al., 2019; Lokko \& Stern, 2014) as well as among those older in age (Kunzmann et al., 2014). Therefore, the present study specifically focused on the role of sadness and its effect on risky medical decision making among younger and older adults. Based on limited empirical research inducing sadness (e.g., Chou et al., 2007; Treffers et al., 2016), it was expected that after a sadness induction, participants would be less risk taking relative to participants in a neutral condition. Moreover, there is some evidence (e.g., Chou et al., 2007) that age may moderate the association between sadness and risk taking. Indeed, it was expected that older adults in the sad condition would be less risk taking than younger adults in 
the sad condition. Additionally, theory posits that sadness is characterized by high appraisal tendencies of uncertainty and situational control (Smith \& Ellsworth, 1985), which are thought to explain the link between sadness and subsequent decision making (Lerner \& Keltner, 2000). Thus, it was expected that participants in the sad condition would report high appraisals of uncertainty and situational control, which would explain why they were less risk taking relative to those in the neutral condition. Lastly, theoretical work (Kunzmann et al., 2014) suggests that age may moderate the association between sadness and appraisals of situational control. Based on the tenets of the discrete emotions approach, it was expected that older adults in the sad condition would report higher appraisals of situational control than younger adults in the sad condition. See Figure 1 for the hypothesized moderated mediation model of the present study.

\section{Research Aims and Hypotheses}

Research Aim 1. The first aim of the current study was to examine the effect of video condition on risky medical decision making and explore whether the appraisal tendencies of uncertainty and situational control accounted for this association.

Hypothesis 1a. Because both younger and older adults induced to feel sad have shown less risk taking tendencies than those in a neutral video condition (Chou et al., 2007; Treffers et al., 2012), it was hypothesized that participants in the sad video condition would make less risky medical decisions than those in the neutral video condition. Hypothesis 1b: Sadness is characterized by appraisal dimensions of uncertainty and situational control, which have been proposed to explain why sadness is related to subsequent decisions (Lerner \& Keltner, 2000, 2001). It was hypothesized that the sad video condition would no longer be significantly associated with less risky medical decisions when controlling for higher appraisals of situational control and uncertainty. 
Research Aim 2. The second aim of the current study was to examine the association between age and risky medical decision making.

Hypothesis 2. Although research on age and risky medical decision making suggests that there may not be age differences in this domain (Butler et al., 2012; Hanoch et al., 2018; Rosman et al., 2013), there are limitations to using the medical subscale of the DOSPERT which may account for the lack of age differences. Research on age and health/safety decisions suggests that older adults are less risk taking than younger adults (Bonem et al., 2015; Rolison et al., 2013; Shook et al., 2019). Therefore, utilizing a different measure of risky medical decision making may shed light that older adults are less risk taking in the medical domain, too. It was hypothesized that older adults would make less risky medical decisions than younger adults.

Research Aim 3. The third aim of the current study was to examine the effect of age as a moderator on the association between video condition and risky decision making, as well as video condition and appraisals of situational control.

Hypothesis 3a. The discrete emotions approach suggests that sadness may be more salient and intense in older adults relative to younger adults (Kunzmann et al., 2014). Further, one study showed that older adults in a sad video condition were less risk taking than younger adults in the sad video condition (Chou et al., 2007). Therefore, it was hypothesized that older adults in the sad condition would make less risky medical decisions than younger adults in the sad condition.

Hypothesis 3b. Older adults tend to experience a higher prevalence of losses in life than younger adults (Lindenberger \& Baltes, 1997), as well as a decline in personal control (Kunzmann et al., 2014). Therefore, it was hypothesized that older adults in the sad 
condition would report higher appraisals of situational control than younger adults in the sad condition.

\section{Method}

\section{Participants}

Participants $(N=300)$ living within the United States were recruited through CloudResearch. CloudResearch is a crowdsourcing site that is connected to Amazon's Mechanical Turk programming interface, but allows researchers more control over the exclusion criteria. A stratified sampling strategy was used to recruit an age and sex diverse sample: 150 younger adults (aged 18-35; 75 male, 75 female) and 150 older adults (aged 60+; 75 male, 75 female). A power analysis ( $\mathrm{G}^{*}$ Power; Erdfelder et al., 1996) indicated that a sample size of 166 was required to detect an effect of .10 for a linear multiple regression testing for significant $R^{2}$ increase, assuming power is .80 and $\alpha=.05$.

All participants were from the U.S. and had HIT approval rates of 95\% or higher. Using the CloudResearch pro features, responses from the same IP address and same geolocation were blocked to reduce duplicate responses and potential bots from taking the survey. Participants were asked to report their current age two different times throughout the survey. Seven participants inconsistently reported their age and were excluded from analyses. Another attention check was placed at the end of the survey in the form of an open-ended question. This attention check asked participants to describe the video clip they watched at the beginning of the survey. Twenty-three participants failed this attention check (e.g., blank answer, non-sensical response) and were excluded from analyses. Thus, the sample $(N=270)$ consisted of 128 younger adults 
$($ aged $18-35, M=28.91, S D=3.88)$ and 142 older adults $($ aged $60-89, M=66.92, S D=5.63){ }^{2}$

There were a relatively equal number of females (51.5\%) and males $(47.0 \%)$, with $1.5 \%$

identifying as other. Participants were mostly White (77\%). For additional demographic

information see Table 1 .

\section{Procedure}

After providing consent, participants first reported their age and sex. They then completed an assessment of baseline affect. Next, participants were randomly assigned to the sad or neutral video condition and watched the designated video clip. After watching the video, participants were randomly presented with the three risky medical decision making scenarios and measures of appraisal tendencies for each scenario. ${ }^{1}$ The order in which participants received each decision making scenario was recorded on Qualtrics. Next, participants were presented with measures to assess perceptions of risks and benefits of Treatment B (higher risk option) relative to Treatment A (lower risk option). Then, participants completed measures of familiarity with the medical scenarios and treatments, perceived health, health consciousness, health anxiety, and social support in a randomized order. Demographic questions were presented last. All study

\footnotetext{
${ }^{2}$ One attention check was embedded approximately mid-way through the survey and stated "Please click on the answer "Agree"'. No participants failed this attention check. Chi-square analyses revealed that participants excluded $(n=30)$ did not significantly differ from the final sample $(n=270)$ based on video condition, sex, race, income, education, or marital status ( $p$ s $>$ $.05)$. However, chi-square analyses showed that the groups did significantly differ based on age group $(p<.05)$, such that more younger adults were excluded than older adults. Additionally, $t$ tests showed that those who were excluded reported significantly greater risky decision making $(t(298)=-4.88, p<.001)$, higher appraisals of uncertainty $(t(47.24)=-2.34, p=.02)$, and higher appraisals of situation control $(t(39.86)=-5.44, p<.001)$ compared to the final sample. ${ }^{1}$ Three ANOVAs were conducted to test for potential order effects. The order in which participants were presented with the risky decision scenarios was entered as the IV and risky decision making, uncertainty, and situational control were entered as the DV of each ANOVA. There was not a significant effect on overall risky decision making $(F(2,267)=0.60, p=.55)$, appraisals of uncertainty $(F(2,267)=0.32, p=.73)$ or appraisals of situational control $(F(2,267)$ $=0.79, p=.46$ ).
} 
sessions took approximately 35 minutes to complete. Each participant received $\$ 1.00$ U.S. for their participation.

Participants were recruited to sign up for the study via CloudResearch and were automatically redirected to complete the study through Qualtrics. The use of crowdsourcing sites allows for rapid collection of data and typically provides a large, diverse participant pool (Buhrmester et al., 2016). Data from crowdsourcing sites has also shown to be as reliable and valid as data obtained through traditional methods (Buhrmester et al., 2016). Data from MTurk typically provides a more demographically diverse participant pool than community samples (Paolacci \& Chandler, 2014; Weigold et al., 2013).

\section{Materials}

Participants were randomly assigned to the neutral or sad video condition. There were 65 younger and 82 older adults in the neutral video condition and 78 younger and 68 older adults in the sad video condition.

Sad video condition. A pilot study was conducted using a U.S. sample of younger and older adults (Appendix P). Two videos, The Champ and Marley and Me, were used to induce sadness. There were no age differences in self-reported sadness following the videos. Because age was a main variable of interest for the present study, it was important to identify an affective stimulus that did not produce an age effect. Additionally, participants who watched Marley and Me reported greater sadness following the video than those who watched The Champ. Thus, Marley and Me was chosen for the purpose of the present study because the video did not produce an age effect and appeared to induce greater sadness than the other video. This 2-minute clip shows a family having to put down their dog because he is sick. This video has also been used in prior research (Schwartz et al., 2018). 
Neutral video condition. In the control condition, participants watched a 2 minute video clip about the Great Barrier Reef from a National Geographic special. This clip is considered to induce a neutral state. Although the pilot study indicated that younger adults reported a greater neutral state (e.g., unemotional, indifferent) than older adults after watching the video (Appendix P), this video has been used as a control condition in prior work that has also induced sadness in U.S. samples (Cryder et al., 2008; Lerner et al., 2004; 2013).

\section{Measures}

Baseline affect. An adapted version of the Positive and Negative Affect Schedule (PANAS; Watson et al., 1988) was used to assess affect at baseline (Appendix A). The original version of the PANAS does not include multiple adjective to assess sadness or a neutral state. Thus, six additional adjectives were included (i.e., sad, unhappy, blue, neutral, indifferent, unemotional) that reflect sadness and a neutral state. Six original adjectives (i.e., guilty, determined, hostile, ashamed, proud, active) from the PANAS were removed to reduce participant burden and because these adjectives were unrelated to the main study goals. Participants rated the extent to which they felt seven positive (e.g., excited, inspired) and seven negative emotions (e.g., sad, afraid) on a scale from 1 (very slightly or not at all) to 5 (extremely). Items were averaged to compute total positive $(\alpha=.87)$ and negative $(\alpha=.93)$ affect scores, and higher scores indicated more positive and negative affect, respectively.

A composite baseline sadness score was also created by summing the adjectives of sad, unhappy, and blue $(\alpha=.90)$. Sadness at baseline was used as an alternative indicator to test the larger conceptual model.

Risky medical decisions. Participants were presented with three hypothetical medical decision scenarios (Appendix B). Two scenarios were about a serious medical illness and have 
been used in prior research (i.e., cancer, stroke; Bookwala et al., 2001; Strough et al., under review). One additional scenario was created for the purpose of the present study to be equally relevant for people of different ages and was about treatment options for an ankle fracture caused during a car accident. For each scenario, there were two treatment options - Treatment A was lower risk and Treatment B was higher risk. Participants rated their likelihood to choose Treatment A relative to Treatment B on a scale from 1 (most likely to choose Treatment A) to 6 (most likely to choose Treatment B). All scenarios specified that both treatment options were fully covered by insurance to eliminate potential financial burden related to choosing a treatment. Scores were averaged across scenarios and higher scores indicated greater risk taking $(\alpha=.69)$.

Appraisal tendencies. Participants answered items to assess the appraisal tendencies of uncertainty and situational control. Following each of the three medical decision scenarios, participants answered two questions adapted from Ellsworth and Smiths' (1988) Appraisal Questionnaire to assess uncertainty (Appendix C). Each question was rated on a scale from 1 (not at all) to 11 (extremely). Participants were asked "How well could you predict the effectiveness of the treatment in this situation?" and "How uncertain were you about the effectiveness of the treatment in this situation?". The six items ( 2 items per decision scenario) were averaged to create a total uncertainty score $(\alpha=.70)$. Higher scores reflected higher appraisals of uncertainty.

Following each medical decision scenario, participants were presented with three statements that assessed situational control (Appendix C). These items were created for the purpose of the present study and were modeled off of Levenson's (1972) locus of control measure, as well as Wallston and Wallston's (1978) health locus of control measure. After each medical decision scenario, participants responded to the following: "Whether or not the 
treatment is effective is mostly a matter of luck," "The effectiveness of the treatment is greatly influenced by fate," and "The effectiveness of the treatment is beyond any human's control" on a scale from 1 (strongly disagree) to 7 (strongly agree). The nine items were averaged to create a total situational control score $(\alpha=.95)$ and higher scores reflected higher appraisals of situational control.

Perception of medical risks. Participants were asked to rate how risky they perceived each treatment on a scale from 0 (not at all risky) to 4 (very risky) (Weber et al., 2002) (Appendix D). This was used as a manipulation check to ensure that participants perceived the low-risk treatments to be significantly less risky than the high-risk treatment counterparts. A difference score was computed for the perceived riskiness of the treatment options for the three medical scenarios by subtracting Treatment A from Treatment B. A total perceived riskiness score was then computed by summing the three difference scores. Higher scores indicated that participants perceived Treatment B (higher risk option) to involve greater risks relative to Treatment A (lower risk option).

Benefits of medical risks. Participants were asked to rate how much benefit, in general, they perceived each treatment to have on a scale from 0 (no benefits at all) to 4 (great benefits) (Weber et al., 2002) (Appendix E). This was used to examine whether participants perceived the low-risk treatments to be significantly less beneficial than the high-risk treatment counterparts, because research has shown that participants are more likely to engage in risky behavior when they perceive more benefits (Hanoch et al., 2018). A difference score was computed for the perceived benefits of the treatment options for the three medical scenarios by subtracting Treatment A from Treatment B. A total perceived benefits score was then computed by summing 
the three difference scores. Higher scores indicated that participants perceived Treatment B (higher risk option) to involve greater benefits relative to Treatment A (lower risk option).

Demographic information. Participants provided basic demographic information such as their age, sex, race/ethnicity, education, employment status, marital status, and income (Appendix J).

\section{Covariates}

Familiarity with medical scenarios and treatments. Participants reported whether they and someone they knew has been diagnosed with/had the three medical illnesses/conditions (Appendix F). Response options for each illness/condition were "yes" or "no". Responses of “yes" were coded as 1 and responses as "no" were coded as 0 . A self-illness score was created by taking a sum across the three items. Higher scores indicated that participants had been diagnosed/had more medical conditions. An other-illness score was also created by taking a sum across the three items. Higher scores indicated that participants knew more people whom have been diagnosed/had more medical conditions.

Participants also reported whether they and someone they knew had experienced any of the six treatment options (Appendix F). Response options for each treatment were "yes" or "no." Responses of "yes" were coded as 1 and responses as "no" were coded as 0 . A self-treatment score was created by taking a sum across the six items. Higher scores indicated that participants had more experience with the treatment options. An other-treatment score was created by taking a sum across the six items. Higher scores indicated that participants knew people who had more experience with the treatment options. 
Perceived health (Lawton et al., 1982). One item (i.e., "How would you rate your overall health at the present time?") assessed participants' current health (Appendix G). Participants rated their health on a scale from 1 (excellent) to 4 (poor). The item was reverse scored and higher scores indicated better current health.

Health Consciousness (HC; Hong, 2009). Participants completed the 11-item health consciousness scale to assess their orientation towards their overall health on a scale from 1 (strongly disagree) to 7 (strongly agree) (Appendix H). This scale measured three components of health consciousness: self-health awareness (e.g., "I'm very self-conscious about my health.”), personal responsibility (e.g., "Good health takes active participation on my part."), and health motivation (e.g., "Living life without disease and illness is very important to me."). Combing all three components for a total score has demonstrated acceptable internal consistency $(\alpha=0.85$; Hong, 2009). A mean score was computed across all items and higher scores indicated greater health consciousness $(\alpha=.80)$.

Short Health Anxiety Inventory (SHAI; Salkovskis et al., 2002). Participants completed the 4-item, self-report measure of health anxiety related to the negative consequences of becoming ill (Appendix I). This 4-item scale has demonstrated acceptable internal consistency ( $\alpha$ $=0.72$; Salkovskis et al., 2002). Each item had four statements and participants were instructed to select which statement best described their feelings over the past 6 months. An example question consists of the following statements: "A serious illness would ruin some aspect of my life"; "A serious illness would ruin many aspects of my life"; "A serious illness would ruin almost every aspect of my life"; "A serious illness would ruin every aspect of my life." Participants were allowed to select multiple statements for each question. Each question was scored from 0 to 3 . When multiple statements were endorsed, the score for the highest statement 
was used. A mean score was computed and higher scores reflected greater health anxiety about the negative consequences of becoming ill $(\alpha=.76)$.

Social support (Zimet et al., 1988). The 12-item self-report measure of perceived social support was used to assess participants' perceptions of available support from friends, family, and significant others. Participants rated how they felt about each item ("I get the emotional help and support I need from my family") on a scale from 1 (very strongly disagree) to 7 (very strongly agree). A total score was computed by averaging all items, and higher scores indicated greater perceived social support $(\alpha=.95)$.

\section{Results}

\section{Preliminary Analysis}

Before conducting the main analyses, checks for missingness and assumptions of normality were conducted. There were no missing data on any key study variable. Health anxiety and social support were skewed. A square root transformation was applied to health anxiety which normalized its distribution. However, when social support was transformed using a square root, log, or inverse transformation, it remained skewed. Baseline negative affect and baseline sadness were also both skewed and kurtotic. When each was transformed using a square root, $\log$, or inverse transformation, both remained skewed. When the transformed variables for health anxiety, social support, baseline negative affect, and baseline sadness were included in main analyses instead of untransformed variables the results did not significantly change. For this reason, the raw variables without transformations were reported in the results. Descriptive statistics for key study variables for each age group (younger, older) and video condition (neutral, sad) can be found in Table $2 .^{3}$

${ }^{3}$ Descriptive statistics for individual risky medical decision scenarios can be found in Table S1. 
Baseline affect. Two independent $t$-test were conducted to assess differences in baseline positive and negative affect to check that the neutral and sad video conditions did not differ at baseline. Condition (sad, neutral) was entered as the independent variable and affect (i.e., positive or negative) was the dependent variable. There were no significant differences in baseline positive $(t(268)=1.26, p=.21)$ or negative $(t(268)=0.06, p=.96)$ affect between the video conditions.

Two additional independent $t$-test were conducted to assess differences in baseline positive and negative affect to check for age differences in affect at baseline. Age group (younger, older) was entered as the independent variable and affect (i.e., positive or negative) was the dependent variable. There was a significant difference between younger and older adults on baseline positive affect, $t(268)=-2.11, p=.04$. Older adults $(M=3.21, S D=0.78)$ reported significantly higher levels of positive affect than younger adults $(M=2.99, S D=0.93)$. Additionally, younger adults $(M=1.75, S D=0.85)$ reported significantly higher levels of negative affect than older adults $(M=1.20, S D=0.52), t(268)=6.53, p<.001$. Therefore, main analyses were conducted controlling for baseline positive and negative affect.

Manipulation check. To check whether participants perceived the higher risk treatment option as more risky than the lower risk treatment option, a paired samples $t$-tests was conducted for each of the three medical scenarios (see Table 3). ${ }^{4}$ For all three decision scenarios (i.e., stroke, cancer, ankle fracture), participants perceived Treatment B (higher risk option) as

\footnotetext{
${ }^{4}$ To check whether participants perceived the higher risk treatment option as more beneficial than the lower risk treatment option, a paired samples $t$-tests was conducted for each of the three medical scenarios (see Table 3). For the stroke and ankle fracture scenarios, participants perceived Treatment A (lower risk option) as significantly more beneficial than Treatment B (higher risk option). There was no significant difference in perceptions of benefits for options to treat cancer.
} 
significantly more risky than Treatment A (lower risk option). Thus, the manipulation of the riskiness of the treatments were deemed to be successful because participants perceived the higher risk treatment option (Treatment B) as significantly riskier than the lower risk treatment option (Treatment A).

Covariates. Bivariate correlations among possible covariates including baseline affect, current health, health consciousness, heath anxiety, familiarity with medical scenarios and treatment options, and social support were examined in relation to risky medical decision making (see Table 4). Greater baseline negative affect and greater health anxiety were significantly correlated with greater risky medical decision making. Less perceived social support was also significantly correlated with greater risky decision making. Current health, health consciousness, baseline positive mood and familiarity with medical scenarios and treatment options were not significantly related to risky medical decision making. Thus, only the potential covariates of baseline negative affect, health anxiety, and social support were included in subsequent analyses with risky medical decision making as the outcome.

Demographic characteristics of sex $(1=$ male, $0=$ female $)$, race/ethnicity $(1=$ white, $0=$ not white), marital status $(1=$ in a relationship/married, $0=$ not $)$, employment status $(1=$ employed full-time, $0=$ not $)$, working in the medical field $(1=$ yes, $0=$ no $)$, income, and education were also explored as potential covariates (see Table 5). Those who identified as White and who were employed full-time reported greater risky decision making. Sex, marital status, income, education, and working in the medical field were not significantly related to risky decision making. Thus, only the demographic characteristics of race/ethnicity and employment status were included as covariates in subsequent analyses with risky medical decision making as the outcome. 


\section{Main Analyses}

It was hypothesized that those in the sad video condition would make less risky medical decisions than those in the neutral control (Hypothesis 1a), and that older adults would make less risky medical decisions than younger adults (Hypothesis 2). It was also hypothesized that older adults in the sad condition would make less risky medical decisions than younger adults in the sad condition (Hypothesis 3a). To address these hypotheses, an analysis of covariance (ANCOVA) was conducted with condition (neutral, sad) and age group (younger, older) as the between-subjects factors and risky medical decision making as the dependent variable. Baseline positive and negative affect, health anxiety, social support, race/ethnicity, and employment status were entered as covariates (see Table 6). The statistical assumptions to conduct an ANCOVA were met, and the Levene's test of homogeneity of variance was not significant $(p=.67)$ There were not significant main effects of video condition, $F(1,260)=0.68, p=.41$, or age group, $F(1$, $260)=0.19, p=.67 . .^{5}$ There was also not a significant interaction between video condition and age group, $F(1,260)=0.76, p=.38$. Therefore, Hypotheses 1a, 2, and 3a were not supported.

Hypothesis $1 b$, which stated that the sad video condition would no longer be significantly associated with less risky medical decisions when controlling for higher appraisals of situational control and uncertainty, was dependent on Hypothesis 1a being supported. Thus, Hypothesis $1 \mathrm{~b}$ could not be tested. However, while there was not a significant direct effect of video condition on risky decision making, there still could be an indirect effect through the appraisal tendencies. So, associations between video condition and the appraisal tendencies were tested (Table 2).

\footnotetext{
${ }^{5}$ When no covariates were included in the model, there was a significant main effect of age group, $F(1$, $266)=6.88, p=.009$. Older adults $(M=2.51, S D=1.36)$ made less risky decisions than younger adults $(M=2.95, S D=1.45)$. When only negative affect at baseline was included as a covariate, there were no longer age differences in risky medical decision making. This suggested that age differences in baseline negative affect statistically accounted for why older adults made less risky decisions than younger adults.
} 
There were no significant differences in appraisals of uncertainty or situational control between the neutral and sad video conditions. So, video condition ( $x$ variable) was not significantly related to the appraisal dimensions ( $m$ variables) nor risky decision making ( $y$ variable), and thus, the assumptions necessary to test for mediation and/or indirect effects were not met and Hypothesis $1 \mathrm{~b}$ could not be tested (Baron \& Kenny, 1986).

To address Hypothesis $3 \mathrm{~b}$, which stated that older adults in the sad condition would report higher appraisals of situational control than younger adults in the sad condition, an ANCOVA was conducted. Video condition (neutral, sad) and age group (younger, older) were entered as the between-subjects factors and appraisals of situational control as the dependent variable. Baseline positive and negative affect were included as a covariates. ${ }^{6}$ There was not a significant main effect of video condition, $F(1,264)=3.04, p=.08$. However, there was a significant main effect of age group $(F(1,264)=23.10, p<.001)$ which was modified by an interaction with video condition, $F(1,264)=11.87, p=.001$ (see Figure 2 ). Older adults in the sad video condition reported significantly higher appraisals of situational control than older adults in the neutral video condition (see Figure 3). Therefore, although there was a significant interaction, it was not as predicted and Hypothesis $3 \mathrm{~b}$ was not supported.

\section{Exploratory Analyses}

First risky medical scenario. To test whether there was an effect of video condition on the first risky medical scenario that participants received, an ANOVA was conducted. Age group (younger, older), video condition (neutral, sad), and the first risky medical scenario presented (1 = cancer, $2=$ stroke, $3=$ ankle fracture) were entered as the between-subjects factors and risky decision making for the first scenario they received was entered as the dependent variable. The

\footnotetext{
${ }^{6}$ The pattern and significance of findings remained the same when covariates were not included.
} 
main effect of video condition was not significant $F(1,258)=0.42, p=.52$, nor were the main effects of age group or presentation of risky medical scenario $(p s>.27)$. There were also no significant interactions $(p \mathrm{~s}>.17)$. Therefore, the video condition did not have an effect on the first risky medical decision scenario that participants saw.

Conceptual model with baseline sadness. As mentioned above, video condition (neutral, sad) did not have a significant effect on risky medical decision making nor on the appraisals tendencies. So, the original conceptual model did not meet the statistical assumptions to be tested using video condition as an indicator of the emotion 'sadness'. Therefore, the model was tested using baseline sadness as an alternative indicator of the emotion 'sadness'. Thus, the original hypotheses about the association between sadness and risky decision making, as well as sadness and the appraisal tendencies were tested with baseline sadness. Video condition was included as a covariate in subsequent analyses.

Bivariate correlations (Table 4) were first conducted. Hypothesis 1a stated that sadness would be associated with less risky medical decision making. However, correlations showed that greater sadness at baseline was significantly related to greater risky medical decision making, which was the opposite of Hypothesis 1a. Greater sadness at baseline was significantly correlated with higher appraisals of situational control, as expected, but not associated with appraisals of uncertainty. Older age was related to less sadness at baseline.

A moderated mediation model was tested using the PROCESS macro (Hayes, 2017; Model 8) in SPSS to test baseline sadness as an alternative indicator in the conceptual model. Hypothesis $1 \mathrm{~b}$ stated that sadness would no longer be significantly associated with less risk taking after controlling for appraisals of situational control and uncertainty. It was also hypothesized that the magnitude of the association between sadness and less risk taking would be 
stronger in older adults relative to younger adults (Hypothesis 3a), and that the magnitude of the association between sadness and higher appraisals of situational control would be stronger in older adults relative to younger adults (Hypothesis $3 \mathrm{~b}$ ). Sadness at baseline was entered as the independent variable, appraisals of situational control and uncertainty were entered as the mediators, age group (younger, older) was entered as a moderator, and risky medical decision making was the dependent variable (see Figure 4). Video condition, health anxiety, social support, race, and employment were included as covariates. ${ }^{7}$

The indirect effect of baseline sadness on risky decision making through appraisals of uncertainty $(b=0.01,95 \%$ CI $[-.03, .07])$ and situational control $(b=0.01,95 \%$ CI $[-.04, .07])$ was not significant. Thus, there was not a significant indirect effect of baseline sadness on risky decision making through uncertainty and situational control (Hypothesis 1b). The direct effect of baseline sadness on risky decision making remained significant $(b=.27, p=.01)$. However, as noted previously, the direction of the association was in the opposite direction than predicted. The interaction between baseline sadness and age on risky decision making $(p=.57)$ and the interaction between baseline sadness and age on appraisals of situational control $(p=.52)$ were not significant. Thus, age did not moderate the association between baseline sadness and risky medical decision making (Hypothesis 3a), nor did it moderate the association between baseline sadness and situational control (Hypothesis 3b).

Individual negative affect adjectives. To explore the associations among the seven negative affect adjectives and the three sadness adjectives at baseline with risky decision making, bivariate correlations were computed (see Table 7). All 10 adjectives were significantly related to greater risky decision making. This finding is inconsistent with the appraisal tendency

\footnotetext{
${ }^{7}$ The pattern and significance of findings remained the same when covariates were not included.
} 
framework, which posits that two emotions may be of the same valence, yet give rise to different cognitive and motivational processes, consequently leading to different decisions (Lerner \& Keltner, 2000; 2001). It is important to note that the magnitude of these correlation coefficients were small to moderate ( $r$ s .18-.31; Cohen, 1988).

\section{Discussion}

Risky medical decision making often occurs under a negative affective state and has consequential impacts on the trajectory of well-being (Carpenter \& Niedenthal, 2018; Ferrer \& Mendes, 2018). While these types of decisions are common across adulthood, they often become more frequent with increasing age (Leventhal et al., 2015). The present findings aimed to address the shortcomings of the literature by investigating the effect of a sad video induction on risky medical decision making, as well as the association between age and risky decision making. Although the sad video induction did not have an effect on decision making, discrete sadness at baseline was related to greater risky medical decision making, which was opposite of what was hypothesized. Additionally, while older age was related to less risky medical decision making, this findings was no longer significant after accounting for baseline negative affect.

Though sadness has been theoretically identified as a discrete emotion that is of particular relevance in the domain of medical decision making (Derry et al., 2019), the present findings demonstrate that those who watched the sad video did not significantly differ in risky medical decision making relative to those who watched the neural video. Limited empirical work has induced sadness to test the effect on risky decision making. However, some evidence indicates that those who watched a sad video tended to show less risk-taking behavior in the context of hypothetical financial and life dilemma scenarios compared to those who watched a neutral video (Chou et al., 2007; Treffers et al., 2012). There is no research to date exploring how 
induced emotions influence risky decision making across multiple decision domains (e.g., medical, financial) within the same study. This is an important area for future work to address in order to further understand potential domain differences in risk taking.

Because research on the induction of discrete emotions and risk taking is still in its infancy, it is unclear why the sad video induction did not have an effect on risky medical decision making. Although the sad video in the present study was pilot tested and found to be effective at inducing sadness, this is the first study to use this video to test the effect of sadness on risky decision making. Future research should aim to utilize other videos and different induction techniques to further explore the effect of sadness on risky medical decision making.

Since there was no significant effect of the sad video condition on decision making, an exploratory analysis was conducted with baseline sadness used as an alternative indicator in the conceptual model. Findings showed that higher levels of sadness at baseline were associated with greater risky medical decision making. This finding is surprising and opposite of what would be expected. To my knowledge, this is the first study to explore the effect of sadness on risky decisions in the medical domain, and hypotheses were mainly based on risky decisions in the financial domain. Financial decisions typically involve money, which is replaceable and can be earned back. The riskier options for medical treatments in the current study involved the potential consequences of worse quality of life or dying. Because life or better health cannot be regained, these inherent domain differences may explain this differential pattern of findings. As noted above, more work is necessary to understand how induced emotions affect risk taking in different decision domains. Potentially, the effect of sadness on risky decision making may vary across domains, and thus, operate differently within the domain of medical decisions. It is important to note that exploring the relation between baseline sadness and risky decision making 
was exploratory, and thus, may be a spurious correlation such that the association is due to a third variable (Simon, 1954).

Theoretical work posits that sadness is characterized by high appraisals of uncertainty and situational control when faced with a negative event (Lerner \& Keltner, 2000; Smith \& Ellsworth, 1985). Yet, there is limited empirical work testing this assumption. The present study found that those who watched the sad video did not significantly differ in appraisals of uncertainty or situational control relative to those who watched the neural video. However, baseline sadness was related to higher appraisals of situational control but not related to appraisals of uncertainty. These findings provide partial empirical support of a link between sadness and appraisal tendencies (Lerner \& Keltner, 2000; Smith \& Ellsworth, 1985). Because appraisal tendencies, which are specific to certain emotions, are proposed to influence subsequent decision making (Lerner \& Keltner, 2000), it then follows that high appraisals of uncertainty and situational control should explain the link between sadness and risky decision making. However, this proposition has not yet been empirically tested in the literature. In the present study, a mediation analysis showed that the appraisal tendencies did not account for the association between baseline sadness and greater risk taking. Therefore, it is unclear why sadness at baseline was linked to greater risky decision making, as well as why this association was in the opposite direction than predicted.

It is important to note that all negative emotions at baseline were significantly associated with greater risky decision making (see Table 7), which is inconsistent with the predictions of the appraisal tendency framework (Lerner \& Keltner, 2000; 2001). According to the appraisal tendency framework, two emotions of the same valence may give rise to distinctive cognitive and motivational processes, ultimately leading to different decision making. Thus, baseline 
negative emotions in the present study do not appear to be operating as expected since each negative emotion was similarly related to decision making. However, it's important to note that empirical work that supports the appraisal tendency framework (e.g., Lerner et al., 2001; Lerner et al., 2013) generally involves comparing negative emotions that are experimentally induced, whereas the current findings on baseline affect are not induced emotions but rather real-life emotional experiences which may account for the inconsistency.

While the associations between negative emotions and risky decision making in the current study are inconsistent with the predictions of the appraisal tendency framework which focuses on discrete emotions (Lerner \& Keltner, 2000), the findings also contrast predictions made based on theories of broad negative affect. According to theories focused on the relation between broad negative affect and risk taking, it would be predicted that greater negative affect is related to less risky medical decision making. For example, the affect infusion model argues that negative affect causes a person to view the world as a threat, and thus, should consequently cause less risky decision making (Forgas, 1994; 1995). Similarly, the affect heuristic suggests that an individual should be less risk taking because negative affect should cause greater perceived risks associated with a decision (Slovic et al., 2005). Yet, findings in the present study are inconsistent with the predictions derived from these theories and show that broad negative affect at baseline was related to greater risky medical decision making. Moreover, greater negative affect at baseline was related to perceiving Treatments B (higher risk option) as less risky than Treatments A (lower risk option), and these perceived risks statically reduced the association between negative affect and risky decision making (see Appendix O). Thus, because those in a greater negative mood at baseline perceived the higher risk options (Treatment B) to involve less 
risks than the lower risk options (Treatment A), the present data are inconsistent with these theories.

In contrast to the predictions from the affect infusion model and affect heuristic that negative affect is associated with less risky decisions, the mood-maintenance hypothesis posits that people experiencing high levels of negative affect want to mitigate their negative mood and in order to do so, these people will engage in more risk taking as a means of obtaining greater potential gains (Isen \& Patrick, 1983). In the current study, greater negative affect at baseline was related to perceiving Treatments B (higher risk option) as more beneficial than Treatments A (lower risk option), and these perceived benefits statically reduced for the association between negative affect and risky decision making (see Appendix O). Thus, because those in a greater negative mood at baseline perceived the higher risk options (Treatment B) to involve the chance to obtain greater benefits than the lower risk options (Treatment A), the present data lend initial support to the mood-maintenance hypothesis.

Only three studies have explored age differences in risky medical decision making and all three studies utilized the medical subscale of the DOSPERT (Butler et al., 2012; Hanoch et al., 2018; Rosman et al., 2013). The medical subscale of the DOSPERT does not assess risky decisions that a patient with a critical condition would face (Hanoch et al., 2013), whereas the scenarios used in the current study more accurately capture the diagnosis and treatment of a serious medical condition or injury. Although initial evidence using the medical DOSPEERT suggests that there may not be age differences in the medical domain, the current study showed that older adults made less risky medical decisions than younger adults, which contrasts prior work. This suggests that the type of medical decisions assessed may matter when trying to understand age differences in this domain. However, the current study then expanded upon prior 
research by accounting for age differences in baseline negative affect, and found that age was no longer significantly related to risky decision making. This suggests that age differences in baseline negative affect statistically accounted for why older adults made less risky decisions than younger adults.

At baseline, younger adults reported higher levels of negative affect and lower levels of positive affect than older adults, which is consistent with prior research on age differences in emotional experiences (Carstensen et al., 2000; Löckenhoff \& Carstensen, 2004). Researchers have shown that age differences in risk taking varies across domains (Bonem et al., 2015; Rolison et al., 2014). However, less work has investigated whether age differences in emotional experiences account for the link between older age and less risk taking. For example, while research demonstrates that older adults tend to make less risky health/safety, financial, recreational, and ethnical decisions than younger adults (e.g., Bonem et al., 2015; Rolison et al., 2014; Rosman et al., 2013; Shook et al., 2019), these findings have not accounted for age differences in affect. Findings from the current study emphasize the importance of examining how age-related emotional experiences are related to, and may account for, age differences in risk taking.

One previous study demonstrated that after a sad video induction, older adults were less risk taking than younger adults, which provided initial evidence that age might moderate the association between sadness and risky decision making (Chou et al., 2007). The present study did not find a significant interaction between age and the sad video condition, nor between age and baseline sadness, on risky medical decision making. Because there is a scarcity of empirical work in this area and Chou et al. (2007) used a different video to induce sadness, these findings are difficult to interpret. However, Chou et al. (2007) found that the sad induction was stronger 
for older adults relative to younger adults, which they noted may explain their pattern of findings. The sad video in the present study was pilot tested and there was no evidence of age differences in self-reported sadness following the induction, which is a strength of this study. More work is necessary to explore the relation between age, sadness, and risky decision making, and it is important for future research to utilize inductions that are equally effective among younger and older adults.

The discrete emotions approach to aging discusses how older age is related to an increased experience of losses and declines across life domains, which are thought to be related to a decline in personal control (Kunzmann et al., 2014). Thus, this theory suggests that older adults should report higher appraisals of situational control than younger adults. However, findings showed that younger adults reported higher appraisals of situation control than older adults, which is opposite of what was expected. Additionally, the present study tested the interaction between age and the sad video condition on situational control and showed that among older adults, those who watched the sad video reported higher appraisals of situational control than those who watched the neutral video. This finding highlights the importance of sadness, such that that older adults who experienced sadness also reported higher appraisals of situation control or a sense that outcomes are based on factors beyond individual control. Nonetheless, the interaction between age and baseline sadness on situational control was not significant. Given the scarcity in empirical work focusing on appraisal dimensions, future researchers should continue to explore the influence of appraisals dimensions, as well as other characteristics of sadness, such as core relational components (i.e., loss and helplessness; Smith \& Lazarus, 1993). It is also unclear why induced sadness and baseline sadness appear to be operating differently. Because baseline sadness was based on a participants' real-life emotion and induced sadness was based on the 
fictional situation of someone else, this may explain the differential patterns between the two indicators of sadness.

Altogether, the findings of the present study should be considered within the context of the COVID-19 pandemic, as data were collected during February 2021. The context of the pandemic may have influenced participants' risky medical decisions because these medical treatments involved being in a public place (e.g., doctor's office/hospital setting) which posed its own risk of catching COVID-19. The pandemic has been a time of heightened distress (Xiong et al., 2020) and research has shown that distress (e.g., stress, depression, anxiety) has increased from prepandemic to during the pandemic (Daly et al., 2020; Pierce et al., 2020). However, it's important to note that even during the pandemic, well-documented age differences in emotional experiences have been maintained, such that older adults have reported lower levels of anxiety and depression relative to younger adults (Bruine de Bruine, 2020; Wilson et al., 2020), which is consistent with research conducted pre-pandemic (see Charles \& Carstensen, 2010, for a review). Additionally, younger adults in the present study reported higher appraisals of situational control than older adults. Potentially, this may reflect the context of the pandemic, such that younger adults are experiencing a heightened sense of loss of control over aspects of their lives (Stewart \& Healy, 1989).

\section{Limitations and Future Directions}

The present research has strengths and limitations that provide a foundation for future research. First, it's important to note that although the manipulation of the riskiness of the treatments was successful, participants' scores on risky decision making tended to be skewed towards the lower risk option (Treatment A) relative to the higher risk option (Treatment B). Further, participants perceived Treatment A (lower risk option) to be more beneficial than 
Treatment B (higher risk option) for two of the medical scenarios. Thus, participants, regardless of age group and video condition, may have trended toward choosing the less risky option because they perceived it to be both less risky and more beneficial than the high risk option. Indeed, work suggests that risks and benefits tend to be inversely related, which is why individuals who perceive an option as involving high risk also perceive that option as less beneficial (Alhakami and Slovic, 1994). However, there are situations in which risks and benefits are positively correlated, such that the option involving high risk also has high benefits. To further understand risky medical decision making, future work should utilize a measure where the riskier option is also more beneficial than the less risky option. Additionally, it's unclear what the benefits were that participants perceived. For example, did participants perceive Treatment A (lower risk) to be more beneficial because it was less risky, because of the likelihood of being 'cured', because it made them more confident in their decision, or another reason? More research is necessary to understand how perceived benefits affect risky decision making, and what exactly these benefits are that participants perceive.

Second, the data in the present study are cross-sectional and cannot address cohort effects (Schaie, 1983). More research investigating the effects of context and cohort on risky medical decision making across adulthood is necessary, such as the implementation of cohort sequential designs to tease out the effects of historical cohort and changes in decision making with age (Schaie \& Batles, 1975). Third, the data are self-report and may not accurately map onto realworld risk behaviors. Although using hypothetical decision scenarios has shown to predict realworld behaviors (Bruine de Bruin et al., 2007), using hypothetical scenarios limits the ecological validity of the risk-taking task. For example, given the hypothetical nature of the decisions, participants' induced emotions may not mimic the real-life emotional experiences that are 
associated with risky medical decision making. Further, only three medical conditions (i.e., stroke, cancer, ankle fracture) were assessed in the present study and may not generalize to other medical conditions. Future research should explore additional, common medical conditions (e.g., heart disease, Alzheimer's disease; CDC, 2020).

Fourth, the use of online crowdsourcing cites for data collection introduces problems related to users completing the survey more than once, workers creating bots, and inattentive participants (Goodman et al., 2013; Paolacci \& Chandler, 2014). However, the present study utilized the pro features of CloudResearch to block duplicate IP addresses and geolocations from taking the survey, as well as employed three attention checks throughout the survey to screen for inattentive participants. Nonetheless, future work should use other sampling methods. Fifth, the video induction was brief (i.e., 2 minutes) and may not have been intense enough, which may explain why there was not an effect of the sad video condition on risky decision making. However, it is important to note that the sad video was piloted tested and was shown to be effective at inducing sadness. Moreover, the pilot study demonstrated comparable levels of induced sadness between younger and older adults. Nevertheless, future work should use other mood induction techniques (e.g., autobiographical recall), which may have stronger, longerlasting effects.

\section{Conclusion}

The present study's findings provide evidence that age differences in risky medical decisions may be dependent upon the type of medical decisions assessed and age-related emotional experiences. Additionally, the findings suggest that a sad induction may not have the same effect on risky medical decisions relative to other risky decisions (e.g., financial). The potential consequences of the medical decisions in the present study involved worse quality of 
life or death, which are irrevocable and may explain why decision making in the medical domain operates differently than other decision domains. Future research should utilize this assessment of risky medical decision making to continue to explore decision making within this domain. 


\section{References}

Agarwal, S., Driscoll, J. C., Gabaix, X., \& Laibson, D. (2009). The age of reason: Financial decisions over the life cycle and implications for regulation. Brookings Papers on Economic Activity, 2009(2), 51-117. https://www.brookings.edu/wpcontent/uploads/2016/07/2009b_bpea_agarwal.pdf

Bodenhausen, G. V. (1993). Emotions, arousal, and stereotypic judgments: A heuristic model of affect and stereotyping. In Affect, cognition and stereotyping (pp. 13-37). Academic Press. https://doi.org/10.1016/B978-0-08-088579-7.50006-5

Bonem, E. M., Ellsworth, P. C., \& Gonzalez, R. (2015). Age differences in risk: Perceptions, intentions and domains. Journal of Behavioral Decision Making, 28(4), 317-330. https://doi.org/10.1002/bdm.1848

Blais, A. R., \& Weber, E. U. (2006). A domain-specific risk-taking (DOSPERT) scale for adult populations. Judgment and Decision making, 1(1).

Bookwala, J., Coppola, K. M., Fagerlin, A., Ditto, P. H., Danks, J. H., Smucker, W. D. (2001). Gender differences in older adults' preferences for life-sustaining medical treatments and end-of-life values. Death studies, 25(2), 127-149. https://doi.org/10.1080/07481180126202

Botti, S., \& Iyengar, S. S. (2006). The dark side of choice: When choice impairs social welfare. Journal of Public Policy \& Marketing, 25(1), 24-38. https://doi.org/10.1509/jppm.25.1.24

Buhrmester, M., Kwang, T., \& Gosling, S. D. (2016). Amazon's Mechanical Turk: A new source of inexpensive, yet high-quality data? In A. E. Kazdin (Ed.), Methodological issues and 
strategies in clinical research (p. 133-139). American Psychological

Association. https://doi.org/10.1037/14805-009

Butler, S., Rosman, A., Seleski, S., Garcia, M., Lee, S., Barnes, J., \& Schwartz, A. (2012). A medical risk attitude subscale for DOSPERT. Judgment \& Decision Making, 7(2), 189195.

Bruine de Bruin, W., Parker, A. M., \& Fischhoff, B. (2007). Individual differences in adult decision-making competence. Journal of Personality and Social Psychology, 92(5), 938 956. https://doi.org/10.1037/0022-3514.92.5.938.

Bruine de Bruin, W., McNair, S. J., Taylor, A. L., Summers, B., \& Strough, J. (2015). “Thinking about numbers is not my idea of fun" Need for cognition mediates age differences in numeracy performance. Medical Decision Making, 35(1), 22-26.

Carpenter, S. M., \& Niedenthal, P. M. (2018). Emotional processes in risky and multiattribute health decisions. Psychology \& Health, 33(1), 58-76. https://doi.org/10.1080/08870446.2017.1314478

Carstensen, L. L., Pasupathi, M., Mayr, U., \& Nesselroade, J. R. (2000). Emotional experience in everyday life across the adult life span. Journal of Personality and Social Psychology, 79(4), 644-655. https://doi.org/10.1037/0022-3514.79.4.644

Carstensen, L. L., Fung, H. H., \& Charles, S. T. (2003). Socioemotional selectivity theory and the regulation of emotion in the second half of life. Motivation and Emotion, 27(2), 103123. https://doi.org/10.1023/A:1024569803230

Carstensen, L. L. (2006). The influence of a sense of time on human development. Science, 312(5782), 1913-1915. https://doi.org/10.1126/science.1127488 
Carstensen, L. L., Shavit, Y. Z., \& Barnes, J. T. (2020). Age advantages in emotional experience persist even under threat from the COVID-19 pandemic. Psychological Science, 0956797620967261.

Charles, S. T. (2010). Strength and vulnerability integration: a model of emotional well-being across adulthood. Psychological Bulletin, 136(6), 1068. https://doi.org10.1037/a0021232

Chou, K. L., Lee, T., \& Ho, A. H. (2007). Does mood state change risk taking tendency in older adults? Psychology and Aging, 22(2), 310-318. https://doi.org/10.1037/0882-

\subsection{2 .2 .310}

Cryder, C. E., Lerner, J. S., Gross, J. J., \& Dahl, R. E. (2008). Misery is not miserly: Sad and self-focused individuals spend more. Psychological Science, 19(6), 525-530. https://doi.org/10.1111/j.1467-9280.2008.02118.x

Derry, H. M., Epstein, A. S., Lichtenthal, W. G., \& Prigerson, H. G. (2019). Emotions in the room: Common emotional reactions to discussions of poor prognosis and tools to address them. Expert Review of Anticancer Therapy, 19(8), 689-696. https://doi.org/10.1080/14737140.2019.1651648

DeSteno, D., Gross, J. J., \& Kubzansky, L. (2013). Affective science and health: The importance of emotion and emotion regulation. Health Psychology, 32(5), 474-486.

\section{https://doi.org/10.1037/a0030259}

DeSteno, D., Petty, R. E., Wegener, D. T., \& Rucker, D. D. (2000). Beyond valence in the perception of likelihood: The role of emotion specificity. Journal of Personality and Social Psychology, 78(3), 397-416. https://doi.org/10.1037/0022-3514.78.3.397

Edlund, B., \& Sneed, N. V. (1989). Emotional responses to the diagnosis of cancer: Age-related comparisons. In Oncology Nursing Forum, 16(5), 691-697. 
Ellis, E. M., Klein, W. M., Orehek, E., \& Ferrer, R. A. (2018). Effects of emotion on medical decisions involving tradeoffs. Medical Decision Making, 38(8), 1027-1039. https://doi.org/10.1177/0272989X18806493

Erdfelder, E., Faul, F., \& Buchner, A. (1996). GPOWER: A general power analysis program. Behavior Research Methods, Instruments, \& Computers, 28(1), 1-11.

Fajula, C., Bonin-Guillaume, S., Jouve, E., \& Blin, O. (2013). Emotional reactivity assessment of healthy elderly with an emotion-induction procedure. Experimental Aging Research, 39(1), 109-124. https://doi.org/10.1080/0361073X.2013.741961

Fernández-Aguilar, L., Ricarte, J., Ros, L., \& Latorre, J. M. (2018). Emotional differences in young and older adults: Films as mood induction procedure. Frontiers in Psychology, 9, 1110.

Ferrer, R., Klein, W., Lerner, J. S., Reyna, V. F., \& Keltner, D. (2016). Emotions and Health Decision-Making: Extending the Appraisal Tendency Framework to Improve Health and Healthcare. In C. Roberto \& I. Kawachi (Eds.), Behavioral economics and public health. Cambridge, MA: Harvard University Press.

Ferrer, R. A., \& Mendes, W. B. (2018). Emotion, health decision making, and health behaviour. Psychology \& Health, 33(1), 1-16. https://doi.org/10.1080/08870446.2017.1385787

Ferrer, R. A., \& Ellis, E. M. (2019). Moving beyond categorization to understand affective influences on real world health decisions. Social and Personality Psychology Compass, 13(11), 1-16. https://doi.org/10.1111/spc3.12502

Folkman, S., Lazarus, R. S., Pimley, S., \& Novacek, J. (1987). Age differences in stress and coping processes. Psychology and Aging, 2(2), 171-184. https://doi.org/10.1037/0882$\underline{7974.2 .2 .171}$ 
Forgas, J. P. (1994). The role of emotion in social judgments: An introductory review and an Affect Infusion Model (AIM). European Journal of Social Psychology, 24(1), 1-24. https://doi.org/10.1002/ejsp.2420240102

Forgas, J. P. (1995). Mood and judgment: the affect infusion model (AIM). Psychological Bulletin, 117(1), 39- 66. https://doi.org/10.1037/0033-2909.117.1.39.

Gilman, T. L., Shaheen, R., Nylocks, K. M., Halachoff, D., Chapman, J., Flynn, J. J., ... \& Coifman, K. G. (2017). A film set for the elicitation of emotion in research: A comprehensive catalog derived from four decades of investigation. Behavior Research Methods, 49(6), 2061-2082.

Goodman, J. K., Cryder, C. E., \& Cheema, A. (2013). Data collection in a flat world: The strengths and weaknesses of Mechanical Turk samples. Journal of Behavioral Decision Making, 26(3), 213-224. https://doi.org/10.1002/bdm.1753

Gross, J. J., \& Levenson, R. W. (1995). Emotion elicitation using films. Cognition \& Emotion, 9(1), 87-108. https://doi.org/10.1080/02699939508408966

Grühn, D., Sharifian, N., \& Chu, Q. (2016). The limits of a limited future time perspective in explaining age differences in emotional functioning. Psychology and Aging, 31(6), 583593. https://doi.org/10.1037/pag0000060

Hanoch, Y., Rolison, J. J., \& Freund, A. M. (2018). Does medical risk perception and risk taking change with age? Risk Analysis, 38(5), 917-928. https://doi.org/10.1111/risa.12692

Hazer, D., Ma, X., Rukavina, S., Gruss, S., Walter, S., \& Traue, H. C. (2015). Emotion elicitation using film clips: Effect of age groups on movie choice and emotion rating. In C. Stephanidis (Ed.), HCI International 2015 - Posters' Extended Abstracts: International Conference, HCI International 2015, Los Angeles, CA, USA, August 2-7, 
2015. Proceedings, Part I (pp. 110-116). Cham: Springer International Publishing. http://doi.org/10.1007/978-3-319-21380-4_20

Hess, T. M., Strough, J., \& Löckenhoff, C. (Eds.). (2015). Aging and decision making: Empirical and applied perspectives. Elsevier Academic Press.

Hewig, J., Hagemann, D., Seifert, J., Gollwitzer, M., Naumann, E., \& Bartussek, D. (2005). A revised film set for the induction of basic emotions. Cognition and Emotion, 19(7), 10951109.

Hong, H. (2009). Scale development for measuring health consciousness: Reconceptualization. that Matters to the Practice, 212-234.

Isen, A. M., \& Patrick, R. (1983). The effect of positive feelings on risk taking: When the chips are down. Organizational Behavior and Human Performance, 31(2), 194-202. https://doi.org/10.1016/0030-5073(83)90120-4

Jefferies, L. N., Smilek, D., Eich, E., \& Enns, J. T. (2008). Emotional valence and arousal interact in attentional control. Psychological Science, 19(3), 290-295. https://doi.org/10.1111/j.1467-9280.2008.02082.x

Jenkins, L. M., \& Andrewes, D. G. (2012). A new set of standardized verbal and non-verbal contemporary film stimuli for the elicitation of emotions. Brain Impairment, 13(2), 212227.

Josef, A. K., Richter, D., Samanez-Larkin, G. R., Wagner, G. G., Hertwig, R., \& Mata, R. (2016). Stability and change in risk-taking propensity across the adult life span. Journal of Personality and Social Psychology, 111(3), 430-450. https://doi.org/10.1037/pspp0000090 
Jung, H., \& Young, M. J. (2012). The de-biasing effect of incidental anger on other-provided anchors. Journal of Behavioral Decision Making, 25(5), 435-442. https://doi.org/10.1002/bdm.739

Kring, A. M., \& Gordon, A. H. (1998). Sex differences in emotion: expression, experience, and physiology. Journal of Personality and Social Psychology, 74(3), 686-703. https://doi.org/10.1037/0022-3514.74.3.686

Kunzmann, U., \& Grühn, D. (2005). Age differences in emotional reactivity: The sample case of sadness. Psychology and Aging, 20(1), 47-59. https://doi.org/10.1037/0882-7974.20.1.47

Kunzmann, U., Kappes, C., \& Wrosch, C. (2014). Emotional aging: a discrete emotions perspective. Frontiers in Psychology, 5, 380. https://doi.org/10.3389/fpsyg.2014.00380

Lawton, M. P., Moss, M., Fulcomer, M., \& Kleban, M. H. (1982). A research and service oriented multilevel assessment instrument. Journal of Gerontology, 37(1), 91-99. https://doi.org/10.1093/geronj/37.1.91

Lerner, J. S., \& Keltner, D. (2000). Beyond valence: Toward a model of emotion-specific influences on judgement and choice. Cognition \& Emotion, 14(4), 473-493. https://doi.org/10.1080/026999300402763

Lerner, J. S., \& Keltner, D. (2001). Fear, anger, and risk. Journal of Personality and Social Psychology, 81(1), 146-159. https://doi.org/10.1037//0022-3514.81.1.146

Lerner, J. S., \& Tiedens, L. Z. (2006). Portrait of the angry decision maker: How appraisal tendencies shape anger's influence on cognition. Journal of Behavioral Decision Making, 19(2), 115-137. https://doi.org/10.1002/bdm.515

Lerner, J. S., Li, Y., \& Weber, E. U. (2013). The financial costs of sadness. Psychological Science, 24(1), 72-79. https://doi.org/10.1177/0956797612450302 
Lerner, J. S., Li, Y., Valdesolo, P., \& Kassam, K. S. (2015). Emotion and decision making. Annual Review of Psychology, 66(1), 799-823. https://doi.org/10.1146/annurevpsych-010213-115043

Levenson, R. W. (1992). Autonomic nervous system differences among emotions. Psychological Science, 3(1), 23-27. https://doi.org/10.1111/j.1467-9280.1992.tb00251.x

Leventhal, H., Herold, J., Leventhal, E. A., Burns, E., \& Diefenbach, M. A. (2015). Decisions and actions for life patterns and health practices as we age: A bottom-up approach. In T. M. Hess, J. Strough, \& C. E. Löckenhoff (Eds.), Aging and decision making: Empirical and applied perspectives (p. 283-308). Elsevier Academic Press. https://doi.org/10.1016/B978-0-12-417148-0.00014-5

Lindenberger, U., \& Baltes, P. B. (1997). Intellectual functioning in old and very old age: Crosssectional results from the Berlin Aging Study. Psychology and Aging, 12(3), $410-432$. https://doi.org/10.1037/0882-7974.12.3.410.

Löckenhoff, C. E., \& Carstensen, L. L. (2004). Socioemotional selectivity theory, aging, and health: The increasingly delicate balance between regulating emotions and making tough choices. Journal of Personality, 72(6), 1395-1424. https://doi.org/10.1111/j.1467$\underline{6494.2004 .00301 . x}$

Loewenstein, G., \& Lerner, J. S. (2003). The role of affect in decision making. In R. J. Davidson, K. R. Scherer, \& H. H. Goldsmith (Eds.), Series in affective science. Handbook of affective sciences (pp. 619-642). Oxford University Press.

Loewenstein, G. (2005). Hot-cold empathy gaps and medical decision making. Health Psychology, 24(4S), S49-S56. https://doi.org/10.1037/0278-6133.24.4.S49 
Mamerow, L., Frey, R., \& Mata, R. (2016). Risk taking across the life span: A comparison of self-report and behavioral measures of risk taking. Psychology and Aging, 31(7), 711723. https://doi.org/10.1037/pag0000124

Mata, R., Josef, A. K., \& Hertwig, R. (2016). Propensity for risk taking across the life span and around the globe. Psychological Science, 27(2), 231-243. https://doi.org/10.1177/0956797615617811

Mata, R., Frey, R., Richter, D., Schupp, J., \& Hertwig, R. (2018). Risk preference: A view from psychology. The Journal of Economic Perspectives, 32(2), 155-172. https://doi.org/10.1257/jep.32.2.155

Mather, M. (2012). The emotion paradox in the aging brain. Annals of the New York Academy of Sciences, 1251(1), 33-49. https://doi.org/10.1111/j.1749-6632.2012.06471.x

Mather, M., Mazar, N., Gorlick, M. A., Lighthall, N. R., Burgeno, J., Schoeke, A., \& Ariely, D. (2012). Risk preferences and aging: The "certainty effect" in older adults' decision making. Psychology and Aging, 27(4), 801-816. https://doi.org/10.1037/a0030174

Mikels, J. A., \& Reed, A. E. (2009). Monetary losses do not loom large in later life: Age differences in the framing effect. Journals of Gerontology Series B: Psychological Sciences and Social Sciences, 64(4), 457-460. https://doi.org/10.1093/geronb/gbp043

Mikels, J. A., Shuster, M. M., \& Thai, S. T. (2015). Aging, emotion, and decision making. In T. M. Hess, J. Strough, \& C. E. Löckenhoff (Eds.), Aging and decision making: Empirical and applied perspectives (pp. 169-188). Elsevier Academic Press. 
Mills, C., \& D'Mello, S. (2014). On the validity of the autobiographical emotional memory task for emotion induction. PloS one, 9(4), e95837. https://doi.org/10.1371/journal.pone.0095837

Mroczek, D. K., \& Kolarz, C. M. (1998). The effect of age on positive and negative affect: A developmental perspective on happiness. Journal of Personality and Social Psychology, 75(5), 1333-1349. https://doi.org/10.1037//0022-3514.75.5.1333

Nesse, R. M. (2000). Is depression an adaptation? Archives of General Psychiatry, 57(1), 14-20. https://doi.org/10.1001/archpsyc.57.1.14

Palmore, E. B. (1981). Social patterns in normal aging: Findings from the Duke Longitudinal Study. Duke Univ Press.

Paolacci, G., \& Chandler, J. (2014). Inside the Turk: Understanding Mechanical Turk as a participant pool. Current Directions in Psychological Science, 23(3), 184-188. https://doi.org/10.1177/0963721414531598

Peer, E., Brandimarte, L., Samat, S., \& Acquisti, A. (2017). Beyond the Turk: Alternative platforms for crowdsourcing behavioral research. Journal of Experimental Social Psychology, 70, 153-163. https://doi.org/10.1016/j.jesp.2017.01.006

Peters, E., Hibbard, J., Slovic, P., \& Dieckmann, N. (2007). Numeracy skill and the communication, comprehension, and use of risk-benefit information. Health Affairs, 26(3), 741-748. https://doi.org/10.1377/hlthaff.26.3.741

Reyna, V. F., Nelson, W. L., Han, P. K., \& Dieckmann, N. F. (2009). How numeracy influences risk comprehension and medical decision making. Psychological Bulletin, 135(6), 943973. https://doi.org/10.1037/a0017327. 
Rolison, J. J., Hanoch, Y., Wood, S., \& Liu, P. J. (2014). Risk-taking differences across the adult life span: A question of age and domain. Journals of Gerontology Series B: Psychological Sciences and Social Sciences, 69(6), 870-880. https://doi.org/10.1093/geronb/gbt081

Rosman, A., Garcia, M., Lee, S., Butler, S., \& Schwartz, A. (2013). DOSPERT+ M: A survey of medical risk attitudes in the United States. Judgment and Decision Making, 8(4), 470481.

Salas, C. E., Radovic, D., \& Turnbull, O. H. (2012). Inside-out: comparing internally generated and externally generated basic emotions. Emotion, 12(3), 568-578. https://doi.org/10.1037/a0025811

Salkovskis, P. M., RIMES, K. A., \& WARWICK, H. M. C. (2002). The Health Anxiety Inventory: development and validation of scales for the measurement of health anxiety and hypochondriasis. Psychological Medicine, 32(5), 843-853. DOI:

$10.1017 / \mathrm{S} 0033291702005822$

Samanez-Larkin, G. R., Gibbs, S. E., Khanna, K., Nielsen, L., Carstensen, L. L., \& Knutson, B. (2007). Anticipation of monetary gain but not loss in healthy older adults. Nature Neuroscience, 10(6), 787-791. https://doi.org/10.1038/nn1894

Schaie, W., \& Baltes, P. B. (1975). On sequential strategies in developmental research. Human Development, 18(5), 384-390.

Schaie, K. W. (Ed.). (1983). Longitudinal studies of adult psychological development. New York: Guilford press. 
Seider, B. H., Shiota, M. N., Whalen, P., \& Levenson, R. W. (2011). Greater sadness reactivity in late life. Social Cognitive and Affective Neuroscience, 6(2), 186-194. https://doi.org/10.1093/scan/nsq069

Sheehan, K. B. (2018). Crowdsourcing research: Data collection with Amazon's Mechanical Turk. Communication Monographs, 85(1), 140-156. https://doi.org/10.1080/03637751.2017.1342043

Shook, N. J., Ford, C., Strough, J., Delaney, R., \& Barker, D. (2017). In the moment and feeling good: Age differences in mindfulness and positive affect. Translational Issues in Psychological Science, 3(4), 338-347. https://doi.org/10.1037/tps0000139

Shook, N. J., Delaney, R. K., Strough, J., Wilson, J. M., Sevi, B., \& Altman, N. (2019). Playing it safe: Dispositional mindfulness partially accounts for age differences in health and safety risk-taking propensity. Current Psychology, 1-11. https://doi.org/10.1007/s12144$\underline{019-0137-3}$

Simon, H. A. (1954). Spurious correlation: A causal interpretation. Journal of the American Statistical Association, 49(267), 467-479. https://doi.org/10.1080/01621459.1954.10483515

Slovic, P., Peters, E., Finucane, M. L., \& MacGregor, D. G. (2005). Affect, risk, and decision making. Health Psychology, 24(4S), S35- S40. https://doi.org/10.1037/02786133.24.4.S35.

Smith, C. A., \& Ellsworth, P. C. (1985). Patterns of cognitive appraisal in emotion. Journal of Personality and Social Psychology, 48(4), 813-838.

Stone, R., \& Harahan, M. F. (2010). Improving the long-term care workforce serving older adults. Health Affairs, 29(1), 109-115. https://doi.org/10.1377/hlthaff.2009.0554 
Strough, J., Bruine de Bruin, W., Parker, A. M., Lemaster, P., Pichayayothin, N., \& Delaney, R. (2016). Hour glass half full or half empty? Future time perspective and preoccupation with negative events across the life span. Psychology and Aging, 31(6), 558-573. https://doi.org/10.1037/pag0000097

Strough J., Wilson J., Bruine de Bruin W. (2020). Aging and Financial Decision Making. In Zaleskiewicz T., Traczyk J. (Eds.) Psychological Perspectives on Financial Decision Making. (pp. 167-186). Springer, Cham. https://doi.org/10.1007/978-3-030-45500$\underline{2}-8$

Szasz, P. L., Hofmann, S. G., Heilman, R. M., \& Curtiss, J. (2016). Effect of regulating anger and sadness on decision-making. Cognitive Behaviour Therapy, 45(6), 479-495. https://doi.org/10.1080/16506073.2016.1203354

Thomas, K. A., \& Clifford, S. (2017). Validity and Mechanical Turk: An assessment of exclusion methods and interactive experiments. Computers in Human Behavior, 77, 184197. https://doi.org/10.1016/j.chb.2017.08.038

Treffers, T., Koellinger, P., \& Picot, A. O. (2012). In the mood for risk? A random-assignment experiment addressing the effects of moods on risk preferences. ERIM Report Series Reference No. ERS-2012-014-ORG.

Watson, D., Clark, L. A., \& Tellegen, A. (1988). Development and validation of brief measures of positive and negative affect: the PANAS scales. Journal of Personality and Social Psychology, 54(6), 1063-1070.

Weber, E. U., Blais, A. R., \& Betz, N. E. (2002). A domain-specific risk-attitude scale: Measuring risk perceptions and risk behaviors. Journal of Behavioral Decision Making, 15(4), 263-290. https://doi.org/10.1002/bdm.414 
Weigold, A., Weigold, I. K., \& Russell, E. J. (2013). Examination of the equivalence of selfreport survey-based paper-and-pencil and internet data collection methods. Psychological Methods, 18(1), 53-70. https://doi.org/10.1037/a0031607

Wilson, J. M., Lee, J., Fitzgerald, H. N., Oosterhoff, B., Sevi, B., \& Shook, N. J. (2020). Job insecurity and financial concern during the COVID-19 pandemic are associated with worse mental health. Journal of Occupational and Environmental Medicine, 62(9), 686691. doi: 10.1097/JOM.0000000000001962

Wrosch, C., \& Miller, G. E. (2009). Depressive symptoms can be useful: Self-regulatory and emotional benefits of dysphoric mood in adolescence. Journal of Personality and Social Psychology, 96(6), 1181-1190. https://doi.org/10.1037/a0015172

Wrosch, C., Barlow, M. A., \& Kunzmann, U. (2018). Age-related changes in older adults' anger and sadness: The role of perceived control. Psychology and Aging, 33(2), 350-360. https://doi.org/10.1037/pag0000229

Zikmund-Fisher, B. J., Couper, M. P., Singer, E., Levin, C. A., Fowler Jr, F. J., Ziniel, S., ... \& Fagerlin, A. (2010). The Decisions study: A nationwide survey of United States adults regarding 9 common medical decisions. Medical Decision Making, 30(5_suppl), 20-34. https://doi.org/10.1177/0272989X09353792

Zillman, D., \& Bryant, J. (1984). Affect, Moods and Emotion as Determinants of Selective Exposure. Selective exposure to communication. Hillsdale, NJ, 157-190. 
Table 1

Demographic Characteristics for Each Age Group

\begin{tabular}{|c|c|c|c|c|c|}
\hline \multirow[b]{2}{*}{ Measure } & \multicolumn{2}{|c|}{ Younger Adults } & \multicolumn{2}{|c|}{ Older Adults } & \multirow[b]{2}{*}{ Group Comparison } \\
\hline & $M(n)$ & $S D(\%)$ & $M(n)$ & $S D(\%)$ & \\
\hline Age & 28.91 & 3.88 & 66.92 & 5.63 & $t(268)=-63.95 * * *$ \\
\hline Sex & & & & & $x^{2}(2)=5.12$ \\
\hline Female & 56 & $43.8 \%$ & 71 & $50 \%$ & \\
\hline Male & 68 & $53.1 \%$ & 71 & $50 \%$ & \\
\hline Other & 4 & $3.1 \%$ & - & - & \\
\hline Race/Ethnicity & & & & & $\chi^{2}(5)=27.22 * * *$ \\
\hline White & 81 & $63.3 \%$ & 127 & 89.4 & \\
\hline African American & 17 & $13.3 \%$ & 5 & 3.5 & \\
\hline Asian & 12 & $9.4 \%$ & 3 & 2.1 & \\
\hline Native American & 3 & $2.3 \%$ & 2 & 1.4 & \\
\hline Hispanic & 14 & $10.9 \%$ & 4 & 2.8 & \\
\hline Not reported & 1 & $0.8 \%$ & 1 & 0.7 & \\
\hline Marital Status & & & & & $\chi^{2}(5)=84.33^{* * *}$ \\
\hline Single & 66 & $51.6 \%$ & 14 & $9.9 \%$ & \\
\hline Relationship, not married & 15 & $11.7 \%$ & 10 & $7.0 \%$ & \\
\hline Married & 47 & $36.7 \%$ & 74 & $52.1 \%$ & \\
\hline Separated & - & - & 1 & $0.7 \%$ & \\
\hline Divorced & - & - & 28 & $19.7 \%$ & \\
\hline Widowed & - & - & 15 & $10.6 \%$ & \\
\hline Income & & & & & $\chi^{2}(7)=4.97$ \\
\hline$>\$ 20,000$ & 12 & $9.4 \%$ & 17 & $12.0 \%$ & \\
\hline$\$ 20,000-\$ 39,000$ & 31 & $24.2 \%$ & 37 & $26.1 \%$ & \\
\hline$\$ 40,000-\$ 59,000$ & 33 & $25.8 \%$ & 36 & $25.4 \%$ & \\
\hline$\$ 60,000-\$ 79,000$ & 21 & $16.4 \%$ & 19 & $13.4 \%$ & \\
\hline$\$ 80,000-\$ 99,000$ & 15 & $11.7 \%$ & 12 & $8.5 \%$ & \\
\hline$>\$ 100,000$ & 16 & $12.5 \%$ & 21 & $14.7 \%$ & \\
\hline Education & & & & & $\chi^{2}(9)=19.63 *$ \\
\hline Did not receive high school diploma & 1 & $0.8 \%$ & 1 & $0.7 \%$ & \\
\hline Vocational training & 6 & $4.7 \%$ & 6 & $4.2 \%$ & \\
\hline High school diploma or GED & 12 & $9.4 \%$ & 11 & $7.7 \%$ & \\
\hline Some college & 21 & $16.4 \%$ & 25 & $17.6 \%$ & \\
\hline Associate degree & 6 & $4.7 \%$ & 16 & $11.3 \%$ & \\
\hline Bachelor's degree & 61 & $47.7 \%$ & 38 & $26.8 \%$ & \\
\hline Some graduate work but no degree & 3 & $2.3 \%$ & 8 & $5.6 \%$ & \\
\hline Master's degree & 17 & $13.3 \%$ & 31 & $21.8 \%$ & \\
\hline Professional degree or $\mathrm{PhD}$ & 1 & $0.8 \%$ & 5 & $3.5 \%$ & \\
\hline Other & - & - & 1 & $0.7 \%$ & \\
\hline Employment & & & & & $\chi^{2}(5)=104.05 * * *$ \\
\hline Employed full-time & 80 & $62.5 \%$ & 37 & $26.1 \%$ & \\
\hline Employed part-time & 20 & $15.6 \%$ & 22 & $15.5 \%$ & \\
\hline Not employed, looking for work & 18 & $14.1 \%$ & 2 & $1.4 \%$ & \\
\hline Not employed, not looking for work & 6 & $4.7 \%$ & 6 & $4.2 \%$ & \\
\hline Retired & - & - & 74 & $52.1 \%$ & \\
\hline Other & 4 & $3.1 \%$ & 1 & $0.7 \%$ & \\
\hline Work in medical field & & & & & $\chi^{2}(1)=0.22$ \\
\hline No & 115 & $89.8 \%$ & 129 & $90.8 \%$ & \\
\hline Yes & 13 & $10.2 \%$ & 12 & $8.5 \%$ & \\
\hline Missing & - & - & 1 & $0.7 \%$ & \\
\hline
\end{tabular}

Note. ${ }^{*} p<.05,{ }^{* *} p<.01,{ }^{* * *} p<.001$. 
Table 2

Descriptive Statistics for Key Study Variables by Age Group and Video Condition

\begin{tabular}{|c|c|c|c|c|c|}
\hline \multirow[b]{2}{*}{ Variable } & \multicolumn{2}{|c|}{ Age Group } & \multicolumn{2}{|c|}{ Video Condition } & \multirow[b]{2}{*}{$\begin{array}{c}\text { Total } \\
(\mathrm{n}=270)\end{array}$} \\
\hline & $\begin{array}{l}\text { Younger Adult } \\
\quad(\mathrm{n}=128)\end{array}$ & $\begin{array}{c}\text { Older Adult } \\
(\mathrm{n}=142)\end{array}$ & $\begin{array}{c}\text { Neutral } \\
\text { Condition } \\
(\mathrm{n}=137)\end{array}$ & $\begin{array}{l}\text { Sad Condition } \\
\quad(\mathrm{n}=133) \\
\end{array}$ & \\
\hline & $M(S D)$ & $M(S D)$ & $M(S D)$ & $M(S D)$ & $M(S D)$ \\
\hline $\begin{array}{l}\text { Risky decision } \\
\text { making }\end{array}$ & $2.95(1.45)_{\mathrm{a}}$ & $2.51(1.25)_{\mathrm{b}}$ & $2.66(1.36)_{\mathrm{a}}$ & $2.78(1.37)_{\mathrm{a}}$ & $2.72(1.36)$ \\
\hline Uncertainty & $5.67(1.56)_{\mathrm{a}}$ & $5.84(1.39)_{\mathrm{a}}$ & $5.63(1.74)_{\mathrm{a}}$ & $5.90(1.60)_{\mathrm{a}}$ & $5.76(1.77)$ \\
\hline Situational control & $4.19(1.24)_{\mathrm{a}}$ & $3.23(1.39)_{\mathrm{b}}$ & $3.53(1.41)_{\mathrm{a}}$ & $3.84(1.38)_{\mathrm{a}}$ & $3.68(1.40)$ \\
\hline Negative affect & $1.75(0.84)_{\mathrm{a}}$ & $1.20(0.52)_{b}$ & $1.46(0.68)_{\mathrm{a}}$ & $1.47(0.65)_{\mathrm{a}}$ & $1.46(0.74)$ \\
\hline Positive affect & $2.99(0.93)_{\mathrm{a}}$ & $3.21(0.78)_{\mathrm{b}}$ & $2.93(0.62)_{\mathrm{a}}$ & $2.85(0.61) \mathrm{a}$ & $3.11(0.86)$ \\
\hline Baseline sadness & $1.84(0.99)_{\mathrm{a}}$ & $1.34(0.67)_{\mathrm{b}}$ & $1.54(0.82)_{\mathrm{a}}$ & $1.61(0.92)_{\mathrm{a}}$ & $1.57(0.87)$ \\
\hline Current health & $3.05(0.71) \mathrm{a}$ & $2.97(0.68)_{\mathrm{a}}$ & $3.01(0.69)_{\mathrm{a}}$ & $3.00(0.71) \mathrm{a}$ & $3.01(0.70)$ \\
\hline Health consciousness & $5.14(0.87)_{\mathrm{a}}$ & $5.22(0.75)_{a}$ & $5.19(0.74)_{\mathrm{a}}$ & $5.17(0.87)_{\mathrm{a}}$ & $5.18(0.81)$ \\
\hline Health anxiety & $1.11(0.64)_{\mathrm{a}}$ & $0.83(0.57)_{b}$ & $0.95(0.62)_{\mathrm{a}}$ & $0.97(0.62)_{\mathrm{a}}$ & $0.96(0.62)$ \\
\hline Social support & $5.19(1.32)_{\mathrm{a}}$ & $5.54(1.19)_{\mathrm{b}}$ & $5.41(1.23)_{\mathrm{a}}$ & $5.35(1.30)_{\mathrm{a}}$ & $5.38(1.26)$ \\
\hline Self-illness & $0.19(0.47)_{\mathrm{a}}$ & $0.32(0.56)_{\mathrm{b}}$ & $0.23(0.49)_{\mathrm{a}}$ & $0.28(0.56)_{\mathrm{a}}$ & $0.26(0.52)$ \\
\hline Other-illness & $1.55(1.18)_{\mathrm{a}}$ & $2.08(0.90)_{\mathrm{b}}$ & $1.88(1.05)_{\mathrm{a}}$ & $1.78(1.11)_{\mathrm{a}}$ & $1.83(1.08)$ \\
\hline Self-treatment & $0.68(1.53)_{\mathrm{a}}$ & $0.62(1.09)_{\mathrm{a}}$ & $0.61(1.33)_{\mathrm{a}}$ & $0.69(1.31)_{\mathrm{a}}$ & $0.65(1.32)$ \\
\hline Other-treatment & $3.53(1.61)_{\mathrm{a}}$ & $3.49(1.43)_{\mathrm{a}}$ & $3.50(1.43)_{\mathrm{a}}$ & $3.51(1.58)_{\mathrm{a}}$ & $3.51(1.50)$ \\
\hline Perceived risks & $2.66(2.38)_{\mathrm{a}}$ & $3.80(2.31)_{\mathrm{b}}$ & $3.12(2.44)_{\mathrm{a}}$ & $3.41(2.38)_{\mathrm{a}}$ & $3.26(2.42)$ \\
\hline Perceived benefits & $-0.10(1.96)_{a}$ & $-0.96(2.60)_{b}$ & $-0.40(2.55)_{\mathrm{a}}$ & $-0.71(2.13)_{a}$ & $-0.55(2.35)$ \\
\hline
\end{tabular}

Note. Means with different subscripts under the column of Age Group indicates significant differences between younger and older adults $(p<.05)$. Means with different subscripts under the column of Video Condition indicates significant differences between the neutral and sad condition $(p<.05)$. Higher, positive scores for perceived risks indicates perceiving Treatment B (higher risk option) as more risky than Treatment A (lower risk option). Higher, positive scores for benefits indicates perceiving Treatment B (higher risk option) as more beneficial than Treatment A (lower risk option). 
Table 3

Paired Samples t-tests for Risks and Benefits of Treatment Options

\begin{tabular}{|c|c|c|c|}
\hline Decision Scenario & $\begin{array}{c}\text { Treatment A } \\
M(S D)\end{array}$ & $\begin{array}{c}\text { Treatment B } \\
M(S D)\end{array}$ & Group Comparison \\
\hline
\end{tabular}

Perceived Risks

Stroke

$0.90(1.20)$

$3.03(0.88)$

$t(269)=-22.83 * * *$

Cancer

2.32(1.09)

$3.07(0.81)$

$t(269)=-11.02 * * *$

Ankle Fracture

0.91(1.03)

2.24(1.00)

$t(269)=-19.27 * * *$

Perceived Benefits

Stroke

3.01(0.90)

2.57(0.95)

$t(269)=5.79 * * *$

Cancer

2.63(0.87)

2.71(0.90)

$t(268)=-1.48$

Ankle Fracture

3.07(0.82)

2.86(0.85)

$t(269)=3.58 * * *$

Note. High scores for perceived risks indicates perceiving Treatment B (higher risk option) as more risky than Treatment A (lower risk option). Higher scores for benefits indicates perceiving Treatment B (higher risk option) as more beneficial than Treatment A (lower risk option). ${ }^{*} p<.05, * * p<.01, * * * p<.001$. 
Table 4

Bivariate Correlations and Descriptive Statistics for Key Study Variables

\begin{tabular}{|c|c|c|c|c|c|c|c|c|c|c|c|c|c|c|c|c|c|}
\hline & 1 & 2 & 3 & 4 & 5 & 6 & 7 & 8 & 9 & 10 & 11 & 12 & 13 & 14 & 15 & 16 & 17 \\
\hline 1. Age group & - & & & & & & & & & & & & & & & & \\
\hline 2. Video condition & -.09 & - & & & & & & & & & & & & & & & \\
\hline 3. Risky decision making & $-.16 * *$ & .05 & - & & & & & & & & & & & & & & \\
\hline 4. Uncertainty & .05 & .08 & $.23^{* * *}$ & - & & & & & & & & & & & & & \\
\hline 5. Situational control & $-.34^{* * *}$ & .11 & $.21 * *$ & $.25 * * *$ & - & & & & & & & & & & & & \\
\hline 6. Negative affect & $-.37 * * *$ & -.00 & $.30 * * *$ & $.12^{*}$ & $.33^{* * *}$ & - & & & & & & & & & & & \\
\hline 7. Positive affect & $.13^{*}$ & -.08 & .00 & -.10 & $-.18 * *$ & .04 & - & & & & & & & & & & \\
\hline 8. Baseline sadness & $-.29 * * *$ & .04 & $.25 * * *$ & .08 & $.33^{* * *}$ & $.78 * * *$ & -.08 & - & & & & & & & & & \\
\hline 9. Current health & -.05 & -.01 & .07 & -.07 & .04 & .01 & $.22^{* *}$ & -.05 & - & & & & & & & & \\
\hline 10. Health consciousness & .05 & -.01 & -.04 & -.04 & .12 & -.09 & $.27^{* * *}$ & -.02 & .10 & - & & & & & & & \\
\hline 11. Health anxiety & $-.22 * * *$ & .02 & $.13^{*}$ & .03 & $.22 * * *$ & $.31 * * *$ & $-.15^{*}$ & $.31^{* * *}$ & $-.14^{*}$ & .06 & - & & & & & & \\
\hline 12. Social support & $.14^{*}$ & -.02 & $-.21^{* * *}$ & -.09 & $-.15^{*}$ & $-.24 * * *$ & $.26^{* * *}$ & $-.35^{* * *}$ & $.20 * *$ & $.14^{*}$ & $-.27 * * *$ & - & & & & & \\
\hline 13. Self-illness & $.12^{*}$ & .04 & .05 & .003 & -.04 & .07 & .10 & .02 & -.11 & .07 & -.01 & .10 & - & & & & \\
\hline 14. Other- illness & $.25 * * *$ & -.04 & -.08 & .10 & -.07 & -.01 & .11 & -.001 & .04 & $.15^{*}$ & -.07 & $.13^{*}$ & $.23 * * *$ & - & & & \\
\hline 15. Self-treatment & -.02 & .03 & .07 & .01 & -.06 & .11 & .05 & .04 & -.02 & -.01 & -.04 & .05 & $.53 * * *$ & $.15^{*}$ & - & & \\
\hline 16. Other- treatment & -.01 & .003 & .04 & .11 & .06 & .08 & $.24 * * *$ & .04 & .03 & $.14^{*}$ & -.08 & $.14^{*}$ & $.25^{*}$ & $.64 * * *$ & $.25^{* * *}$ & - & \\
\hline 17. Perceived risks & $.24 * * *$ & .06 & $.21^{-} * * *$ & .01 & $-.13 * *$ & $-.20 * *$ & -.05 & -.10 & $-.14^{*}$ & .12 & .03 & -.04 & .000 & .12 & -.12 & -.12 & - \\
\hline 18. Perceived benefits & $-.18 * *$ & -.07 & $.39 * * *$ & .07 & .11 & $.14^{*}$ & $-.14^{*}$ & $.18^{* *}$ & -.06 & -.08 & $.14^{*}$ & -.06 & -.03 & -.07 & .07 & -.08 & $\begin{array}{c}- \\
.11 \\
\end{array}$ \\
\hline
\end{tabular}

Note. Age $(0=$ younger adult, $1=$ older adult $)$, video condition $(0=$ neutral, $1=$ sad $)$. Higher scores for perceived risks indicates perceiving Treatment B (higher risk option) as more risky than Treatment A (lower risk option). Higher scores for benefits indicates perceiving Treatment B (higher risk option) as more beneficial than Treatment A (lower risk option). ${ }^{*} p<.05,{ }^{* *} p<.01,{ }^{* * *} p<.001$. 
Table 5

Risky Medical Decision Making and Demographic Characteristics

\begin{tabular}{lcc} 
& \multicolumn{2}{c}{ Risky Decision Making } \\
\cline { 2 - 3 } Demographics & $M(S D)$ & Correlation \\
\hline Sex & $2.83(1.37)_{\mathrm{a}}$ & - \\
$\quad$ Male & $2.61(1.36)_{\mathrm{a}}$ & - \\
$\quad$ Female & & \\
Race/ethnicity & $2.62(1.31)_{\mathrm{a}}$ & - \\
$\quad$ White & $3.04(1.50)_{\mathrm{b}}$ & - \\
$\quad$ Not-white & $2.66(1.39)_{\mathrm{a}}$ & - \\
Marital Status & $2.79(1.34)_{\mathrm{a}}$ & - \\
$\quad$ In relationship/married & & - \\
$\quad$ Not in relationship/married & $2.93(1.48)_{\mathrm{a}}$ & - \\
Employment & $2.56(1.24)_{\mathrm{b}}$ & - \\
$\quad$ Employed full-time & & - \\
$\quad$ Not employed full-time & $3.16(1.61)_{\mathrm{a}}$ & - \\
Work in medical field & $2.67(1.32)_{\mathrm{a}}$ & -.04 \\
$\quad$ Yes & - & .11 \\
$\quad$ No & - & \\
Education & & \\
Income & &
\end{tabular}

Note. Means with different subscripts for each demographic characteristic indicates significant differences $(p<.05)$. 
Table 6

Analysis of Covariance Summary for Age and Video Main Effects and Interaction on Risky Medical Decision Making,

Controlling for Baseline Affect

\begin{tabular}{lcccccc}
\hline Predictor & $S S$ & $d f$ & $M S$ & $F$ & $p$ & $\eta_{\mathrm{p}}{ }^{2}$ \\
\hline Age group & 0.31 & 1 & 0.31 & 0.31 & .67 & .001 \\
Video condition & 1.13 & 1 & 1.13 & 0.68 & .41 & .003 \\
Age x Video & 1.25 & 1 & 1.25 & 0.76 & .38 & .003 \\
Negative affect & 26.83 & 1 & 26.83 & 16.29 & $<.001$ & .06 \\
Positive affect & 0.22 & 1 & 0.22 & 0.13 & .72 & .001 \\
Health anxiety & 0.08 & 1 & 0.08 & 0.05 & .83 & .00 \\
Social support & 10.03 & 1 & 10.03 & 6.09 & .01 & .02 \\
Race & 4.99 & 1 & 4.99 & 3.03 & .08 & .01 \\
Employment & 4.87 & 1 & 4.87 & 2.95 & .09 & .01 \\
\hline
\end{tabular}

Note. Age group $(0=$ younger adult, $1=$ older adult $)$, video condition $(0=$ neutral, $1=\operatorname{sad})$, race $(1=$ White, $0=$ not

White), employment ( $1=$ employed full-time, $0=$ not employed full-time). 
Table 7

Bivariate Correlations among Risky Medical Decision Making and Individual Baseline Negative Affect and Sadness Adjectives

\begin{tabular}{|c|c|c|c|c|c|c|c|c|c|c|c|}
\hline & 1 & 2 & 3 & 4 & 5 & 6 & 7 & 8 & 9 & 10 & 11 \\
\hline 1. Risky decision making & - & & & & & & & & & & \\
\hline 2. Distressed & $.26 * * *$ & - & & & & & & & & & \\
\hline 3. Upset & $.31 * * *$ & $.74 * * *$ & - & & & & & & & & \\
\hline 4. Scared & $.31 * * *$ & $.65^{* * *}$ & $.72 * * *$ & - & & & & & & & \\
\hline 5. Jittery & $.25 * * *$ & $.67 * * *$ & $.69 * * *$ & $.70 * * *$ & - & & & & & & \\
\hline 6. Irritable & $.18 * * *$ & $.69 * * *$ & $.66^{* * *}$ & $.60 * * *$ & $.55 * * *$ & - & & & & & \\
\hline 7. Afraid & $.25 * * *$ & $.71 * * *$ & $.71 * * *$ & $.65 * * *$ & $.70 * * *$ & $.54 * * *$ & - & & & & \\
\hline 8. Nervous & $.23 * * *$ & $.69 * * *$ & $.60 * * *$ & $.57 * * *$ & $.69 * * *$ & $.66 * * *$ & $.71 * * *$ & - & & & \\
\hline 9. Sad & $.26 * * *$ & $.68 * * *$ & $.66^{* *}$ & $.58 * * *$ & $.57 * * *$ & $.61 * * *$ & $.57 * * *$ & $.57 * * *$ & - & & \\
\hline 10. Blue & $.20 * * *$ & $.64 * * *$ & $.65^{* * *}$ & $.55 * * *$ & $.59 * * *$ & $.61^{* * *}$ & $.64 * * *$ & $.61 * * *$ & $.81 * * *$ & - & \\
\hline 11. Unhappy & $.24 * * *$ & $.56^{* * *}$ & $.63 * * *$ & $.50 * * *$ & $.55^{* * *}$ & $.53^{* * *}$ & $.59 * * *$ & $.54 * * *$ & $.70 * * *$ & $.75 * * *$ & - \\
\hline
\end{tabular}

Note. ${ }^{*} p<.05, * * p<.01, * * * p<.001$. Higher scores for risky decision making indicate greater risk taking. 


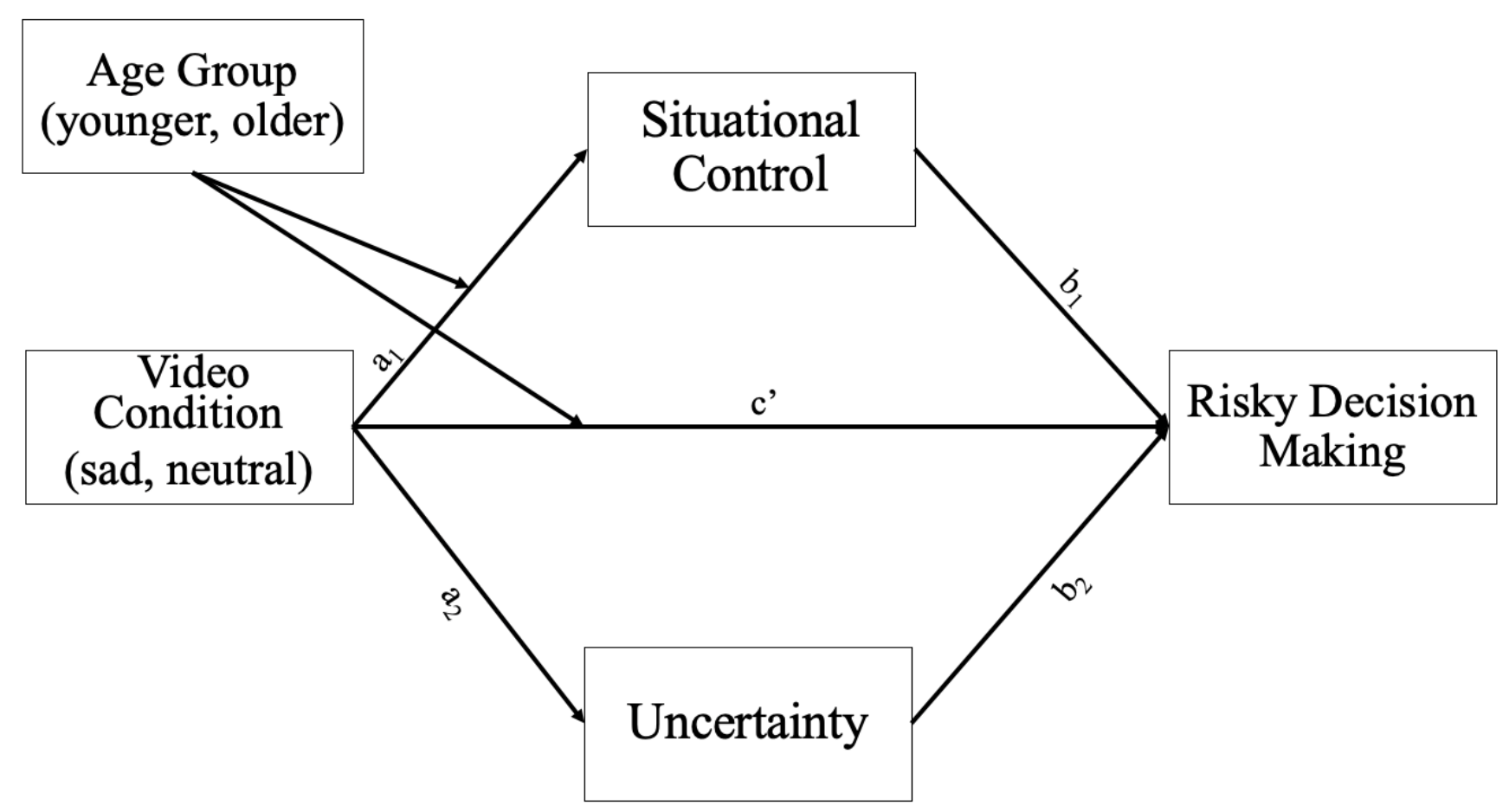

Figure 1. Conceptual moderated mediation model of the effects of sadness and age on risky medical decision making. Video condition used as an indicator of sadness. 


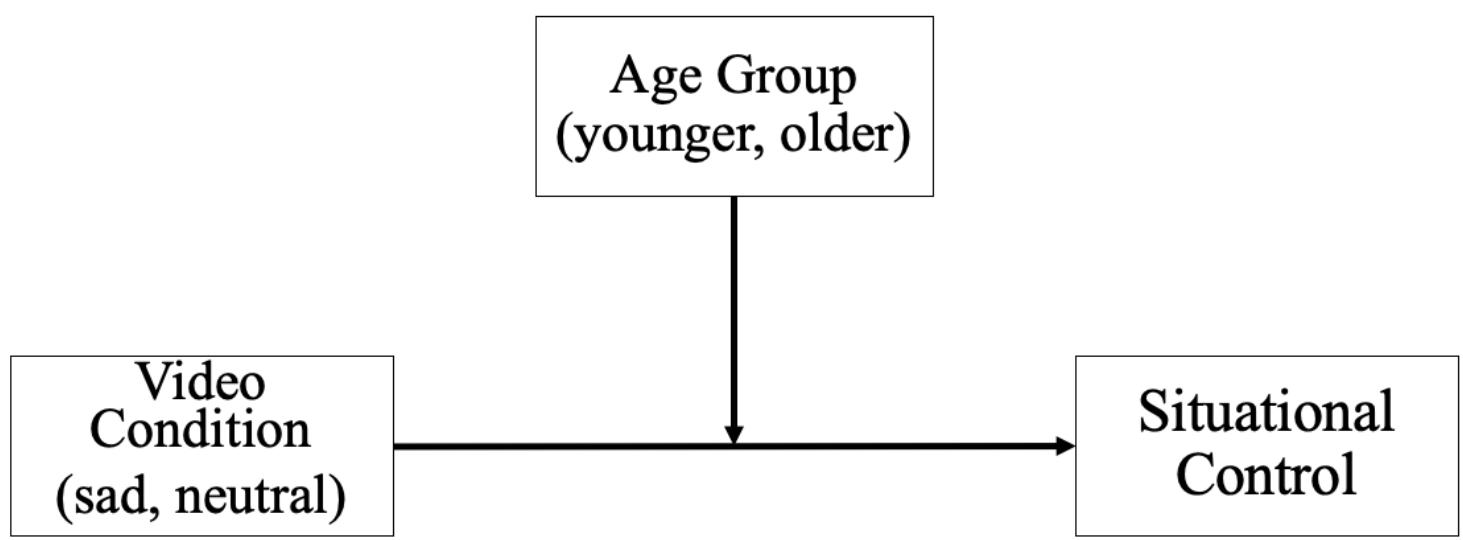

Figure 2. Moderation analysis to test the interaction between video condition and age group on risky medical decision making, while controlling for baseline positive and negative affect. 
5

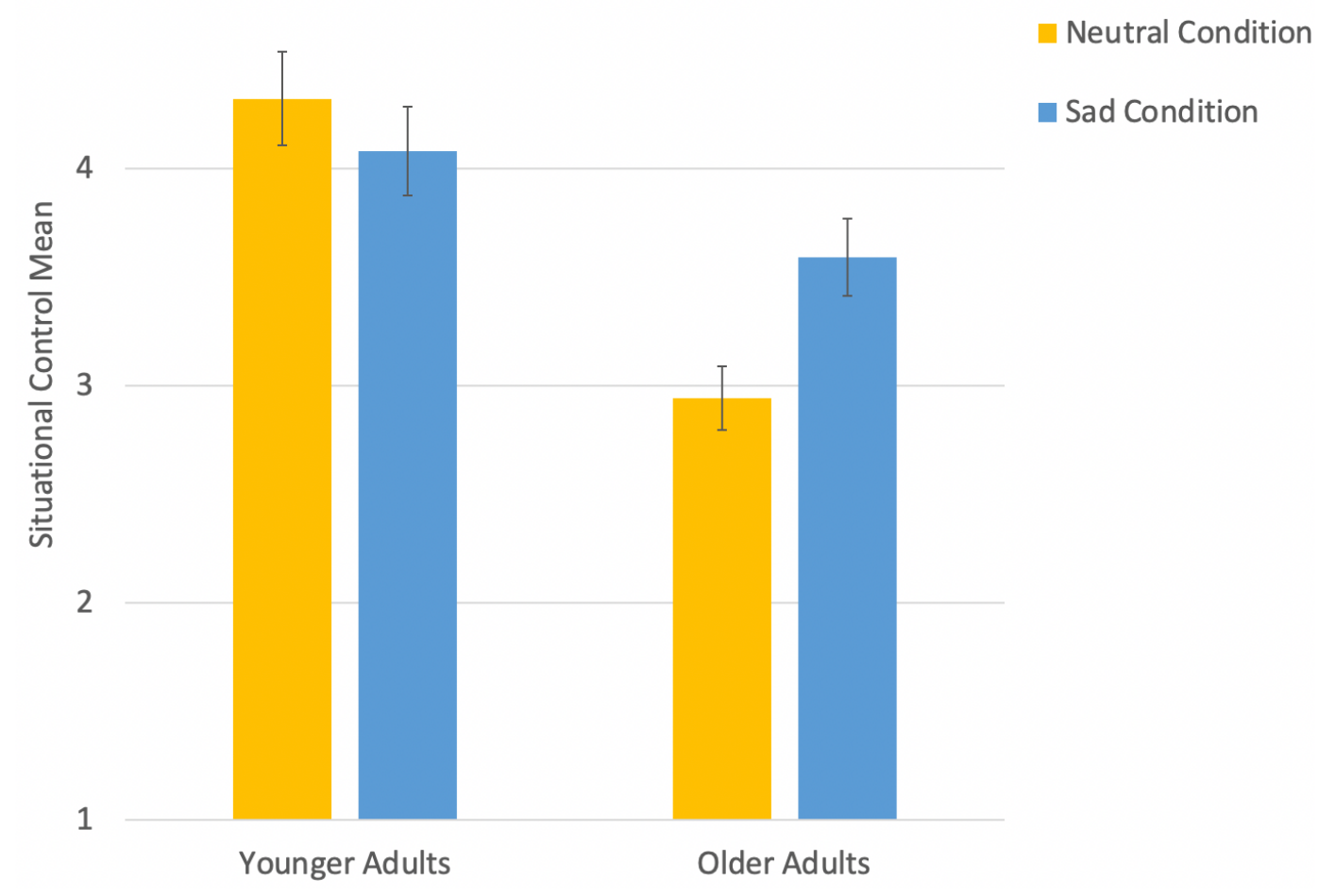

Figure 3. Interaction between age group and video condition on appraisals of situational control, while controlling for positive and negative affect at baseline. Error bars: 95\% CI. 


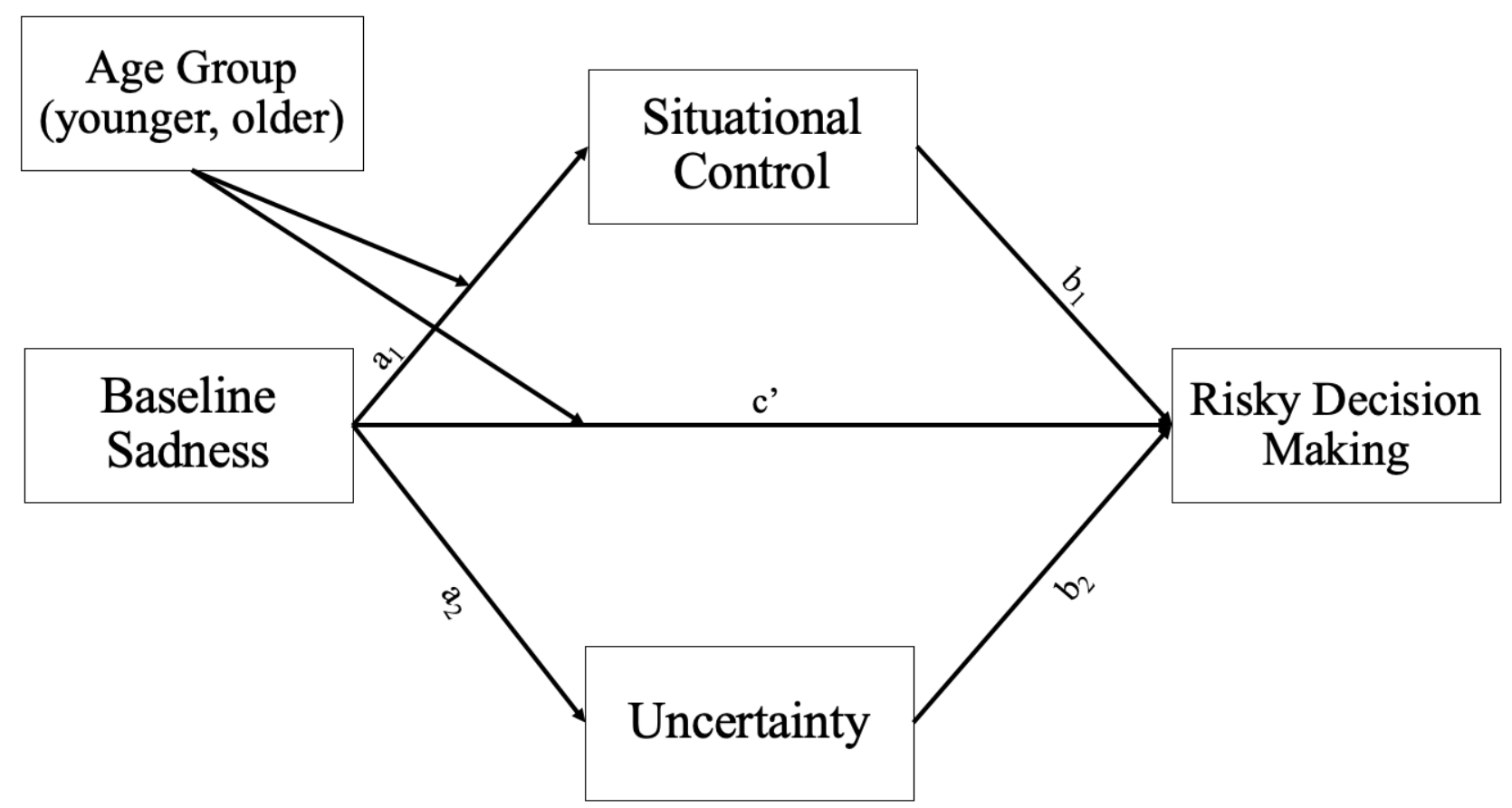

Figure 4. Conceptual moderated mediation model of the effects of sadness and age on risky medical decision making. Sadness at baseline used as an indicator of sadness. 


\section{Appendix A}

\section{Mood}

Instructions: This scale consists of a number of words that describe different feelings and emotions. Read each item and then mark the appropriate answer in the space next to that word. Indicate to what extent you CURRENTLY feel this way, that is, how you feel RIGHT NOW:

$\begin{array}{ccccc}\begin{array}{c}\text { very slightly } \\ \text { or not at all }\end{array} & \text { a little } & \text { moderately } & \text { quite a bit } & \text { extremely } \\ 1 & 2 & 3 & 4 & 5\end{array}$

1. Interested

2. Distressed

3. Alert

4. Excited

5. Upset

6. Inspired

7. Strong

8. Nervous

9. Scared

10. Jittery

11. Enthusiastic

12. Irritable

13. Attentive

14. Afraid

15. Sad

16. Blue

17. Unhappy

18. Neutral

19. Indifferent

20. Unemotional 
Appendix B

\section{Risky Medical Decisions}

(Bookawala et al., 2001; Strough et al., in preparation)

On the next screens, we will ask you to predict the medical decision you would make in different situations. Assume all medical treatments are fully covered by insurance.

\section{SCENARIO 1: Stroke}

Imagine that you have suffered a moderately severe stroke. One arm and one leg are paralyzed. You have trouble speaking and understanding when others speak. You rely on others for help with feeding, dressing, bathing, and toileting. Your doctor says that without treatment, you have a very slight chance of improvement. Assume both treatments are fully covered by insurance. There are two treatment options available:

- Treatment A (Therapy): Treatment A aims to reduce the severity of the symptoms through speech, physical, and occupational therapy. Your doctor says that there is a good chance $(80 \%)$ that the therapy will improve quality of life because it will reduce the severity of your symptoms. There is a small chance $(20 \%)$ there will be no change.

- Treatment B (Surgery): Treatment B aims to reduce the severity of the symptoms through surgery. Your doctor says that if successful, you will be completely cured after the surgery. However, the surgery is risky. There is a very small chance $(5 \%)$ that it may be fatal. There is a 50-50 chance that after the surgery, you will not be cured and things may get worse.

1 (most likely to choose Treatment A - Therapy) 6 (most likely to choose Treatment B Surgery)

\section{SCENARIO 2: Cancer}

Imagine you have cancer that has spread to the liver. You are tired and weak, needing some help with household chores. Your thinking and memory are not affected. You are not in pain. Your doctor says that without treatment, there is no chance of recovery and you would have about six months to live. Assume both treatments are fully covered by insurance. There are two treatments available:

- Treatment A (Radiation Therapy): Treatment A aims to reduce the size of tumors through radiation therapy. Your doctor says that there is a good chance $(80 \%)$ that the therapy will improve your quality of life because it will reduce the severity of your symptoms and increase your chance of living longer than six months. There is a small chance $(20 \%)$ there will be no change.

- Treatment B (Surgery): Treatment B aims to remove the tumors through surgery. Your doctor says that if successful, your quality of life will improve because the surgery will completely eliminate your symptoms and will increase your chance of living longer than one year. However, the surgery is risky. There is a very small (5\%) chance that it may be fatal. There is a 50-50 chance that after the surgery you will not be cured and things may get worse.

1 (most likely to choose Treatment A - Radiation Therapy) 6 (most likely to choose Treatment B - Surgery) 


\section{SCENARIO 3: Ankle Fracture}

Imagine that you have been in a car accident and suffered an ankle fracture due to the impact. You have swelling of the ankle, are in immediate pain, and are unable to walk. Your doctor says that due to the severity of the fracture, there is no chance of recovery without treatment. Assume both treatments are fully covered by insurance. There are two treatment options available:

Treatment A (Cast): Treatment A aims to reduce the severity of the symptoms by repositioning the fractured bone and then immobilizing your ankle in a cast. Your doctor says that there is a good chance ( $80 \%$ ) that the cast will improve quality of life because it will reduce the severity of your symptoms. There is a small chance $(20 \%)$ of poor fracture alignment which will cause joint stiffness and tenderness of the ankle.

Treatment B (Surgery): Treatment B aims to reduce the severity of the symptoms through surgery. Your doctor says that if successful, the surgical implants (i.e., plates and screws) will completely eliminate your symptoms. However, the surgery is risky. There is a very small (5\%) chance that the implant will fail and you will need another operation to correct the complications, which will cause difficulty walking. There is a 50-50 chance that after the surgery you will not be cured and things may get worse.

1 (most likely to choose Treatment A - Cast) 6 (most likely to choose Treatment B - Surgery) 


\section{Appendix C}

\section{Appraisal Tendencies}

Uncertainty (Ellsworth \& Smith, 1988)

1 (not at all) to 11 (extremely).

1. How well could you predict the effectiveness of the treatment in this situation?

2. How uncertain were you about the effectiveness of the treatment in this situation?

\section{Situational Control}

1 (strongly disagree) to 7 (strongly agree)

3. Whether or not the treatment is effective is mostly a matter of luck

4. The effectiveness of the treatment is greatly influenced by fate

5. The effectiveness of the treatment is beyond any human's control 


\section{Appendix D}

\section{Perception of Medical Risks}

(Weber et al., 2002)

For each treatment, please indicate how risky, in general, you think it is from 0 (not at all risky) to 4 (very risky)

1. Speech, physical, and occupational therapy for a stoke.

2. Surgery for a stroke.

3. Radiation therapy for cancer.

4. Surgery for cancer.

5. Cast for an ankle fracture.

6. Surgery for an ankle fracture. 


\section{Appendix E}

\section{Benefits of Medical Risks}

(Strough et al., in preparation)

For each treatment, please indicate how much benefit, in general, you think there is to it from 0 (no benefits at all) to 4 (great benefits)

1. Speech, physical, and occupational therapy for a stoke.

2. Surgery for a stroke.

3. Radiation therapy for cancer.

4. Surgery for cancer.

5. Cast for an ankle fracture.

6. Surgery for an ankle fracture. 


\section{Appendix F}

\section{Familiarity with Medical Scenarios and Treatments}

1. Have you ever been diagnosed with having a stroke? (yes/no)

2. Has someone you know ever been diagnosed with having a stroke? (yes/no)

3. Have you ever been diagnosed with cancer? (yes/no)

4. Has someone you know ever been diagnosed with cancer? (yes/no)

5. Have you ever been diagnosed with an ankle fracture? (yes/no)

6. Has someone you know ever been diagnosed with an ankle fracture? (yes/no)

7. Have you ever had speech, physical, or occupational therapy to treat a stroke? (yes/no)

8. Has someone you know ever had speech, physical, or occupational therapy to treat a stroke? (yes/no)

9. Have you ever had surgery to treat a stroke? (yes/no)

10. Has someone you know ever had surgery to treat a stroke? (yes/no)

11. Have you ever had radiation therapy to treat cancer? (yes/no)

12. Has someone you know ever had radiation therapy to treat cancer? (yes/no)

13. Have you ever had surgery to treat cancer? (yes/no)

14. Has someone you know ever had surgery to treat cancer? (yes/no)

15. Have you ever had a cast to treat an ankle fracture? (yes/no)

16. Had someone you know ever had a cast to treat an ankle fracture? (yes/no)

17. Have you ever had surgery to treat an ankle fracture? (yes/no)

18. Has someone you know ever had surgery to treat an ankle fracture? (yes/no) 
Appendix G

Perceived Health

(Lawton et al., 1982)

How would you rate your overall health at the present time?

$1=$ excellent $\quad 2=$ good $\quad 3=$ fair $\quad 4=$ poor 


\section{Appendix $\mathrm{H}$}

\section{Health Consciousness}

(Hong, 2009)

1 (strongly disagree) and 7 (strongly agree)

1. I'm very self-conscious about my health.

2. I'm generally attentive to my inner feelings about my health.

3. I reflect about my health a lot.

4. I'm concerned about my health all the time.

5. I notice how I feel physically as I go through the day.

6. I take responsibility for the state of my health.

7. Good health takes active participation on my part.

8. I only worry about my health when I get sick. (R)

9. Living life without disease and illness is very important to me.

10. My health depends on how well I take care of myself.

11. Living life in the best possible health is very important to me 


\section{Appendix I}

\section{Short Health Anxiety Inventory}

(Salkovskis et al., 2002)

For the following questions, please think about what it might be like if you had a serious illness of a type which particularly concerns you (such as heart disease, cancer, multiple sclerosis and so on). Obviously you cannot know for definite what it would be like ; please give your best estimate of what you think might happen, basing your estimate on what you know about yourself and serious illness in general.

1. (a) If I had a serious illness I would still be able to enjoy things in my life quite a lot.

(b) If I had a serious illness I would still be able to enjoy things in my life a little.

(c) If I had a serious illness I would be almost completely unable to enjoy things in my life.

(d) If I had a serious illness I would be completely unable to enjoy life at all.

2. (a) If I developed a serious illness there is a good chance that modern medicine would be able to cure me.

(b) If I developed a serious illness there is a moderate chance that modern medicine would be able to cure me.

(c) If I developed a serious illness there is a very small chance that modern medicine would be able to cure me.

(d) If I developed a serious illness there is no chance that modern medicine would be able to cure me.

3. (a) A serious illness would ruin some aspects of my life.

(b) A serious illness would ruin many aspects of my life.

(c) A serious illness would ruin almost every aspect of my life.

(d) A serious illness would ruin every aspect of my life.

4. (a) If I had a serious illness I would not feel that I had lost my dignity.

(b) If I had a serious illness I would feel that I had lost a little of my dignity.

(c) If I had a serious illness I would feel that I had lost quite a lot of my dignity.

(d) If I had a serious illness I would feel that I had totally lost my dignity. 
Appendix J

Multidimensional Scale of Perceived Social Support

(MSPSS; Zimet, Dahlem, Zimet, \& Farley, 1988).

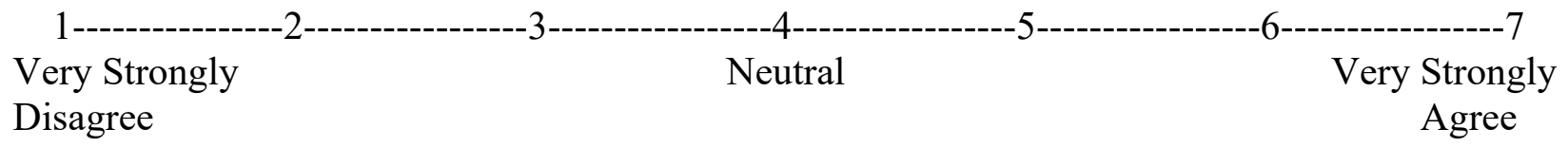

1. There is a special person who is around when I am in need.

2. There is a special person with whom I share my joys and sorrows.

3. - My family really tries to help me.

4. I I I get the emotional help and support I need from my family.

5. I I have a special person who is a real source of comfort to me.

$6 . \quad$ My friends really try to help me.

7. I I can count on my friends when things go wrong.

8. I I can talk about my problems with my family.

9. I I I have friends with whom I can share my joys and sorrows.

10. There is a special person in my life who cares about my feelings.

11. My family is willing to help me make decisions.

12.__ I can talk about my problems with my friends. 


\section{Appendix K}

\section{Demographics}

Sex

Male Female Other

Age

Age:

\section{Marital}

Marital Status (check one):

Single
In a relationship, not married
Married
Separated
Divorced
Widowed

\section{Education}

Education:

Elementary to $8^{\text {th }}$ grade

Some high school (no diploma)

High school graduate (diploma)

Some college, no degree

Associate Degree

Bachelor's degree

Master's degree

Professional degree

Doctorate degree

Other

\section{Race}

Race (check one):

White/Caucasian

African-American/Black

Asian

Native American

Other - Please list:

\section{Ethnicity}

Ethnicity (check one):

Hispanic/Latino

Not Hispanic/Latino 


\section{Employment}

What is your current employment status?

Employed full-time

Employed part-time

Not employed and looking for work

Not employed and not seeking work

Retired

Other

\section{Income}

What is your annual family income?

Less than $\$ 10,000$

$\$ 10,000$ to $\$ 19,999$

$\$ 20,000$ to $\$ 29,999$

$\$ 30,000$ to $\$ 39,999$

$\$ 40,000$ to $\$ 49,999$

$\$ 50,000$ to $\$ 59,999$

$\$ 60,000$ to $\$ 69,999$

$\$ 70,000$ to $\$ 79,999$

$\$ 80,000$ to $\$ 89,999$

$\$ 90,000$ to $\$ 99,999$

$\$ 100,000$ to $\$ 149,999$

$\$ 150,000$ or more 


\section{Appendix L}

\section{Individual Risk Scenarios}

Descriptive statistics for each of the three risk scenarios were computed by age group and video condition (Table S1). Overall, risk taking scores were relatively low across all participants. Older adults were significantly less risk taking than younger adults on the ankle fracture scenario, but there were no significant age differences for the cancer and stroke scenarios. However, there was a trend whereby older adults' risk taking scores were lower than younger adults' scores for the cancer and stroke scenarios. There were also no significant differences in risk taking between the neutral and sad video conditions for any of the three risk scenarios. 
Table S1

Descriptive Statistics for Each Risky Scenario by Age Group and Video Condition

\begin{tabular}{|c|c|c|c|c|c|}
\hline & \multicolumn{2}{|c|}{ Age Group } & \multicolumn{2}{|c|}{ Video Condition } & \multirow[b]{2}{*}{$\begin{array}{c}\text { Total } \\
(\mathrm{n}=270)\end{array}$} \\
\hline \multirow[t]{2}{*}{ Variable } & $\begin{array}{c}\text { Younger } \\
\text { Adult } \\
(\mathrm{n}=128) \\
\end{array}$ & $\begin{array}{l}\text { Older Adult } \\
(\mathrm{n}=142)\end{array}$ & $\begin{array}{c}\text { Neutral } \\
\text { Condition } \\
(\mathrm{n}=137)\end{array}$ & $\begin{array}{c}\text { Sad } \\
\text { Condition } \\
(\mathrm{n}=133)\end{array}$ & \\
\hline & $M(S D)$ & $M(S D)$ & $M(S D)$ & $M(S D)$ & $M(S D)$ \\
\hline Cancer scenario & $3.22(1.77)_{\mathrm{a}}$ & $3.14(1.90)_{\mathrm{a}}$ & $3.10(1.83) \mathrm{a}$ & $3.26(1.85)_{\mathrm{a}}$ & $3.18(1.84)$ \\
\hline Stroke scenario & $2.78(1.76)_{\mathrm{a}}$ & $2.34(1.73)_{\mathrm{a}}$ & $2.45(1.74)_{\mathrm{a}}$ & $2.65(1.77)_{a}$ & $2.55(1.75)$ \\
\hline Ankle fracture scenario & $2.85(1.80)_{\mathrm{a}}$ & $2.06(1.53)_{\mathrm{b}}$ & $2.41(1.70)_{\mathrm{a}}$ & $2.45(1.72)_{\mathrm{a}}$ & $2.43(1.71)$ \\
\hline $\begin{array}{l}\text { Note. Means with differe } \\
\text { differences between you } \\
\text { the column of Video Cor } \\
\text { condition }(p<.05) \text {. }\end{array}$ & $\begin{array}{l}\text { ubscripts un } \\
\text { and older a } \\
\text { on indicates }\end{array}$ & $\begin{array}{l}\text { the column } \\
\text { ts }(p<.05) \text {. } \\
\text { nificant diff }\end{array}$ & $\begin{array}{l}\text { Age Group i } \\
\text { ans with dif } \\
\text { aces betwee }\end{array}$ & $\begin{array}{l}\text { cates signific } \\
\text { ent subscripts } \\
\text { ne neutral and }\end{array}$ & der \\
\hline
\end{tabular}




\section{Appendix M}

\section{Exploring the Moderating Effects of Negative Affect}

To explore whether baseline negative affect moderated the effects of age group or video condition on risky medical decision making, two moderation analyses were conducted using the PROCESS macro for SPSS (Hayes, 2017; Model 1). For the first analysis, age group (younger, older) was entered as the independent variable, negative affect at baseline as the moderator, and risky medical decision making as the dependent variable (see Figure S1). Baseline positive affect, health anxiety, social support, uncertainty, situational control, race, employment, and video condition were entered as covariates. The interaction between age and baseline negative affect was not significant, $(b=-0.38, p=.13)$.

For the second analysis, video condition (neutral, sad) was entered as the independent variable, negative affect at baseline as the moderator, and risky medical decision making as the dependent variable (see Figure S2). Age group, health anxiety, social support, uncertainty, situational control, race, and employment were entered as covariates. The interaction between video condition and baseline negative affect was not significant, $(b=-0.39, p=.10)$. 


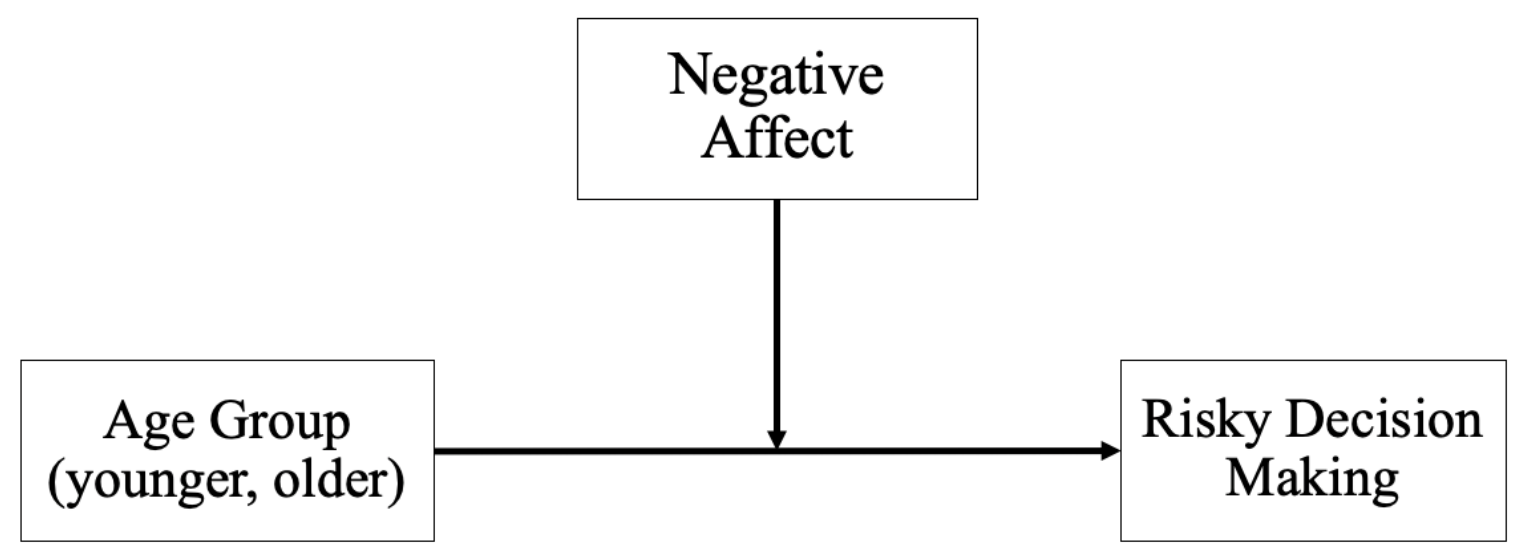

Figure S1. Conceptual moderation analysis to test the interaction between age group and baseline negative affect on risky medical decision making, while controlling for video condition, baseline positive affect, health anxiety, social support, uncertainty, situational control, race, and employment. 


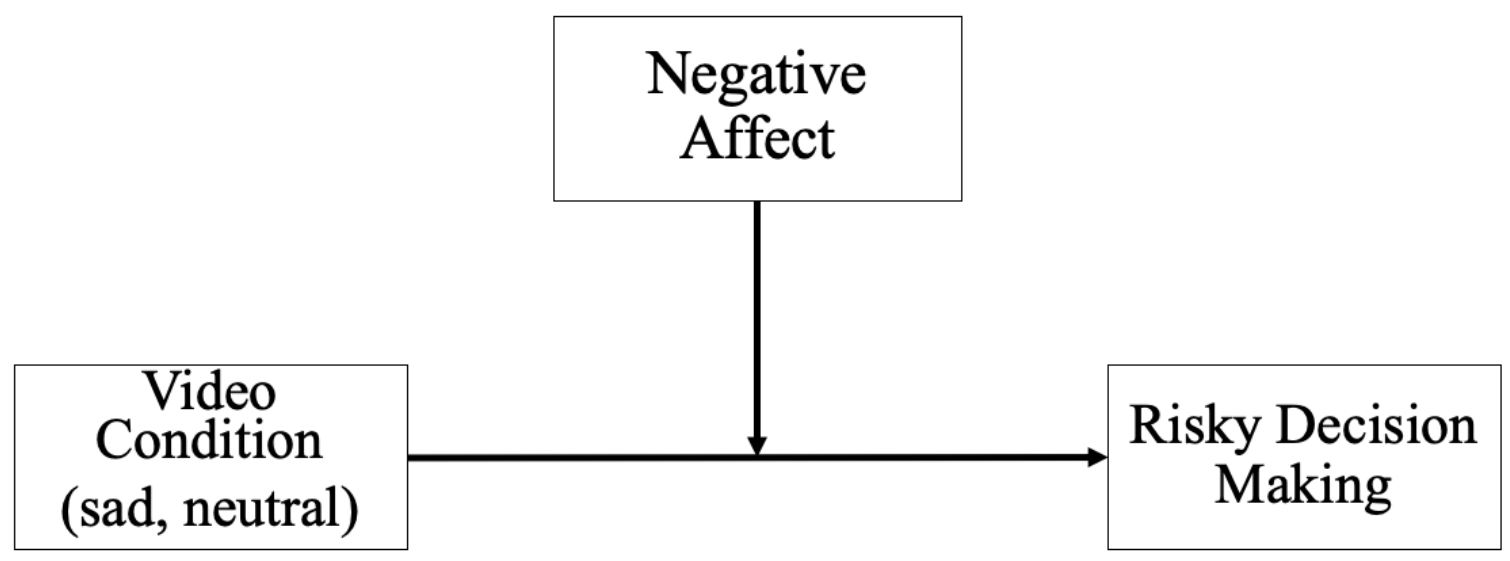

Figure S2. Conceptual moderation analysis to test the interaction between video condition and baseline negative affect on risky medical decision making, while controlling for age group, health anxiety, social support, uncertainty, situational control, race, and employment. 


\section{Appendix N}

\section{Understanding the Association between Age and Risky Decision Making}

To explore whether perceived risks and benefits of the treatment options were important for understanding age and risky decision making, bivariate correlations among age, risky medical decision making, and perceived risks and benefits of the treatments were conducted (see Table 4). Older age was significantly related to perceiving greater risks and less benefits of Treatment B (higher risk option) relative to Treatment A (lower risk option). Greater risky decision making was associated with perceiving less risks and greater benefits of Treatment B (higher risk option) relative to Treatment A (lower risk option).

A mediation analysis was conducted with age group as the independent variable $(x$ variable), perceived risks and perceived benefits as the mediator variables ( $m$ variables), and risky medical decision making as the dependent variable ( $y$ variable) (see Figure S3). Negative affect, positive affect, health anxiety, social support, uncertainty, situational control, race, employment, and video condition were entered as covariates. There was not a significant indirect effect of age on risky decision making through perceived risks $(b=-.05,95 \% \mathrm{CI}[-.15, .003])$ nor perceived benefits $(b=.12,95 \%$ CI $[-.27, .01])$. The direct effect of older age on risky decision making $(b=0.05, p=.78)$ became even stronger $(b=0.22, p=.24)$. Thus, there was a suppressor effect. Additionally, older age was related to greater risky decision making after accounting for the covariates and indirect path. 


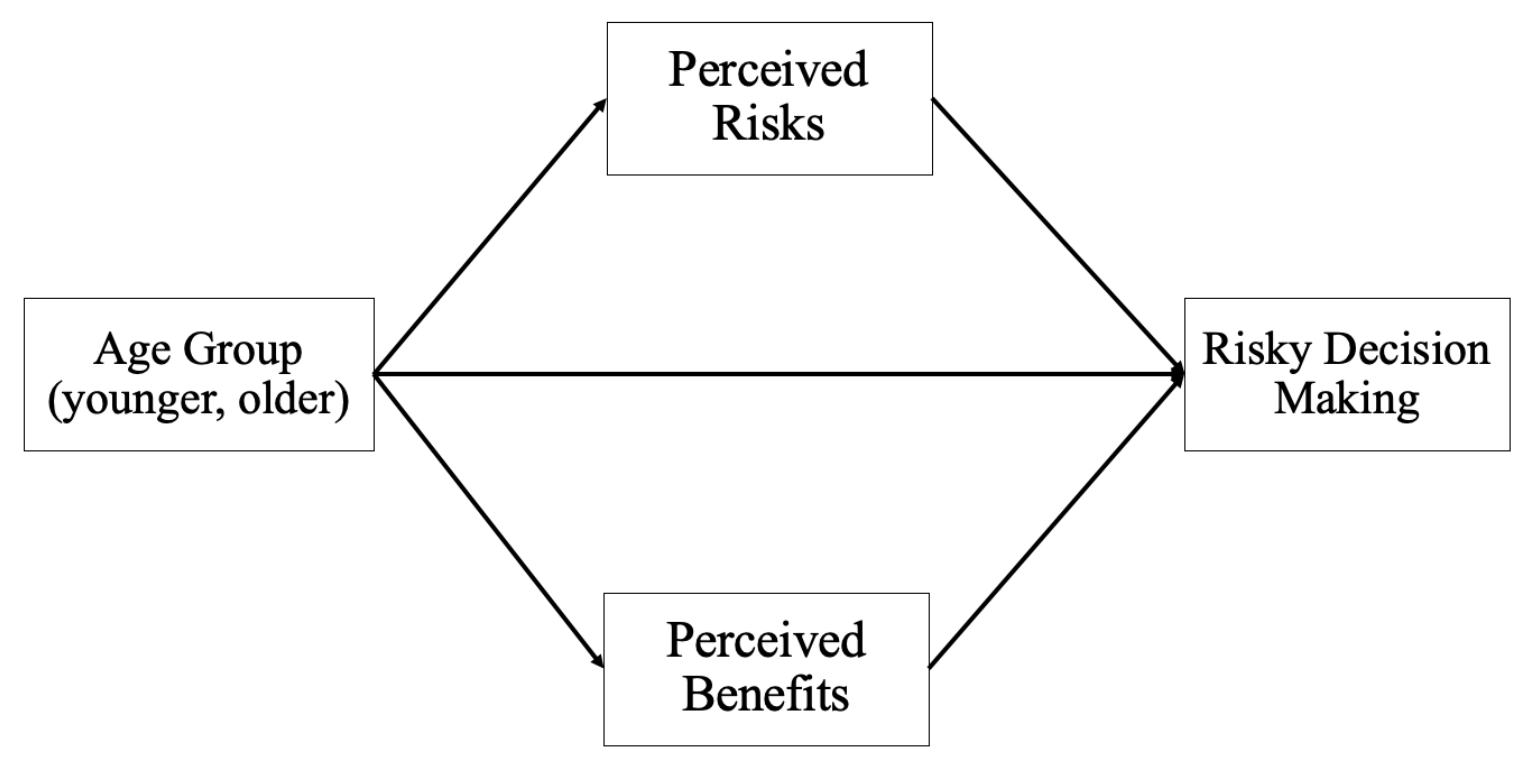

Figure S3. Conceptual mediation analysis to test the indirect effect of age group on risky medical decision making through perceived risks and perceived benefits of the treatment options. Video condition, negative affect, positive affect, health anxiety, social support, uncertainty, situational control, race, and employment included as covariates. 


\section{Appendix O}

\section{Understanding the Association between Negative Affect and Risky Decision Making}

Bivariate correlations (Table 4) indicated that baseline negative affect was associated with greater risky medical decision making, as well as perceiving Treatment B (higher risk option) as less risky and more beneficial than Treatment A (lower risk option). Greater perceived risks of Treatment B (higher risk option) relative to Treatment A (lower risk option) was associated with less risky medical decision making, whereas greater benefits of Treatment B (higher risk option) relative to Treatment A (lower risk option) was also associated with greater risky medical decision making.

To explore whether perceived risks and benefits of the treatment options accounted for the association between negative affect and risky decision making, a parallel mediation analysis was conducted. Negative affect at baseline was entered as the independent variable ( $x$ variable), perceived risks and benefits of the treatments as the mediator variables ( $m$ variables), and risky medical decision making as the dependent variable ( $y$ variable). There was a significant indirect effect of negative affect on risky decision making through perceived risks $(b=.04,95 \% \mathrm{CI}$ $[.003, .12])$ and perceived benefits $(b=.09,95 \%$ CI $[.03, .17])$. The direct effect of negative affect at baseline on risky decision making $(b=0.56, p<.001)$ was reduced $(b=0.43, p<.001){ }^{8}$ This suggested that negative affect was related to greater risky decision making because Treatment B (higher risk) was perceived as less risky and more beneficial than treatment A (lower risk).

\footnotetext{
${ }^{8}$ The indirect effect of negative affect on risky decision making through perceived risks $(b=.03$, $95 \%$ CI $[.001, .10])$, but not perceived benefits $(b=.03,95 \%$ CI $[-.04, .11])$, remained significant after accounting for age group, video condition, race, employment, uncertainty, situational control, health anxiety, and social support.
} 


\section{Appendix $\mathrm{P}$}

\section{Pilot Study}

Limited work has examined age differences in response to emotion induction video clips using a U.S. sample. Thus, a pilot study was conducted to test the efficacy of emotionally evocative video clips in younger and older adults. There were two sad videos and two neutral videos. Aim one was to explore which video per target emotion was more effective at eliciting the target emotion. Aim two was to explore whether there were age differences in emotion ratings following each video clip. Aim three was to explore the discreteness of the target emotion following each video clip.

\section{Methods}

\section{Participants.}

Participants $(N=381)$ living within the United States were recruited through TurkPrime. ${ }^{9}$ A stratified sampling strategy was used to recruit an age diverse sample: 193 younger adults $\left(\right.$ aged $\left.18-38, M_{\text {age }}=27.62, S D=4.16\right)$ and 188 older adults $\left(\right.$ aged $60-88, M_{\text {age }}=65.78, S D=$ 4.79). The majority of participants were female (68\%) and White (75.8\%).

\section{Procedure}

Participants were recruited through TurkPrime and were informed that the study's purpose was to examine people's beliefs and feelings. All participants were required to have demonstrated high performance (95\% or higher) on human intelligence tasks (HITs). Participants with duplicate geolocations and IP addresses were blocked from completing the survey. Participants completed the study measures as part of a larger study. Each participant received a

\footnotetext{
${ }^{9}$ Participants $(N=997)$ were recruited as part of a larger project on emotion induction videos. Those who were excluded were assigned to other emotion conditions (i.e., anger, happiness, disgust) that were not relevant for my dissertation.
} 
$\$ 1.00$ honorarium in exchange for approximately 30 minutes of their time. The study was approved by the West Virginia University Institutional Review Board.

After providing consent, participants reported their age. Next, they completed a measure of baseline mood. Participants were then randomly assigned to one of the four conditions (two sad and two neutral) and watched their respective video clip. ${ }^{10}$ This was a between-subjects design where participants only watched one video. Following the video induction, participants completed another measure of mood as a manipulation check. Lastly, participants provided their demographic information.

\section{Materials}

Four video clips were selected, with two videos used to induce sadness and two videos to induce a neutral state. All videos were from commercially available films or internet programs.

Sadness. Two video clips were selected to induce sadness. The Champ (Gilman et al., 2017; Hewig et al., 2005; Lerner et al., 2004) and Marley and Me (Schwartz et al., 2018) have been used in prior work to induce sadness.

Neutral. Two video clips were selected to a neutral state. National Geographic special of the Great Barrier Reef (Lerner et al., 2004) and a video of nature scenes.

\section{Measures}

Baseline mood. An adapted version of the Positive and Negative Affect Schedule (PANAS; Watson et al., 1988) with additional adjectives included was used to assess mood at baseline. These additional adjectives were added to reflect the emotions of interest. Participants rated the extent to which they felt five positive (e.g., happy, amused) and five negative emotions

\footnotetext{
${ }^{10}$ In the larger study, there were 10 conditions total. There were four discrete emotion conditions (i.e., sadness, anger, happiness, disgust) with two conditions per emotion, as well as two neutral conditions
} 
(e.g., sad, angry) on a scale from 1 (very slightly or not at all) to 5 (extremely). Items were averaged to compute total positive $(\alpha=.63)$ and negative mood $(\alpha=.89)$ scores with higher scores indicating more positive and negative mood, respectively.

Emotional intensity. An adapted version of the PANAS (Watson et al., 1988) with additional adjectives included was used to assess participants' intensity of emotion following the induction videos. Three adjectives were used to assess sadness (e.g., unhappy), anger (e.g., mad), happiness (e.g., joyful), and a neutral state (e.g., unemotional). Two adjectives were used to assess disgust (e.g., repulsed). An additional twelve adjectives were used as fillers (e.g., scared). Participants rated the extent to which they felt each emotion on a scale from 1 (very slightly or not at all) to 5 (extremely). Items were averaged to compute total sadness $(\alpha=.92)$, anger $(\alpha=$ $.95)$, disgust $(\alpha=.91)$, happiness $(\alpha=.93)$, and neutral $(\alpha=.78)$ scores. The average score of each target emotion represented emotional intensity.

\section{Preliminary Analyses}

Two independent $t$-tests were conducted to assess age differences in baseline positive and negative mood. Younger adults $(M=1.44, S D=0.74)$ reported a significantly greater negative mood than older adults $(M=1.20, S D=0.41), t(299.78)=3.80, p<.001$. There were no age differences in positive $\operatorname{mood} t(379)=0.01, p=.99$.

\section{Main Analyses}

\section{Emotional Intensity}


Two ANOVAs were conducted with video clip (video 1 vs. video 2) and age (younger vs. older adult) entered as independent variables and the target discrete emotion (i.e., sadness, neutral) as the dependent variable. ${ }^{11}$

Sadness. There was a significant main effect of video clip, $F(3,185)=20.44, p<.001$, partial $\eta 2=.10$. Marley and $M e(M=3.28, S D=1.16)$ produced significantly greater sadness than The Champ $(M=2.54, S D=1.12)$ within the sample as a whole. There was not a significant main effect of age or interaction between video clip and age $(p s>.05)$. Thus, younger and older adults did not differ in sadness ratings after watching Marley and Me or The Champ.

Neutral. There was a significant main effect of age, $F(3,188)=30.89, p<.001$, partial $\eta 2=.14$. Younger adults $(M=2.33, S D=1.14)$ reported a significantly greater neutral state than older adults $(M=1.60, S D=0.60)$. There was not a significant main effect of video clip or a significant interaction between video clip and age $(p s>.05)$.

\section{Emotional Discreteness}

Four 5 (emotional intensity: neutral, sadness, anger, happiness, disgust) x 2 (age group: younger and older) mixed model ANOVAs were conducted to assess differences in the discreteness of emotions. Age group was entered as a between-subjects variable, and emotional intensity was entered as a within-subjects variable.

The Champ. There was a significant main effect of emotion $(F(4,199.20)=122.84, p<$ $.001)$. There was no significant main effect of age group $(F(1,92)=2.63, p=.11)$. The main effect of emotion was qualified by a significant interaction between age group and emotion,

${ }^{11}$ All patterns and significance of findings remained the same when controlling for positive and negative affect at baseline. 
$F(4,199.20)=3.19, p=.04$. Younger adults $(M=1.82, S D=0.09)$ reported a significantly greater neutral state than older adults $(M=1.32, S D=0.09)$ after watching the video, $p<.001 .^{12}$ There were no other differences in emotional intensity $(p \mathrm{~s}>.05)$.

Marley and Me. There was a significant main effect of emotion $(F(4,200.88)=41.43, p$ $<.001)$. Participants reported greater sadness $(M=2.54, S D=0.12)$ than anger $(M=1.39, S D=$ $0.08)$, happiness $(M=1.50, S D=0.08)$, and disgust $(M=1.40, S D=0.07)$. Participants also reported a greater neutral state $(M=2.03, S D=0.09)$ than anger, happiness, and disgust. There was also a significant main effect of age group $(F(1,93)=4.82, p=.03)$. Younger adults $(M=$ $1.89, S D=0.07)$ reported greater overall emotional intensity than older adults $(M=1.65, S D=$ 0.8). The interaction between age group and emotion was not significant $(p=.49) .{ }^{13}$

Nature scene. There was a significant main effect of emotion $(F(4,187.95)=63.36, p<$ $.001)$. There was also a significant main effect of age group $(F(1,91)=4.32, p=.04)$. The main effects were qualified by a significant interaction between age group and emotion, $F(4,187.95)=$ $7.13, p=.001$. Simple main effects analyses showed that younger adults $(M=2.45, S D=0.13)$ reported a significantly greater neutral state than older adults $(M=1.57, S D=0.14)$. There were no other differences in emotional intensity $(p s>.05)$.

Great Barrier Reef. There was a significant main effect of emotion $(F(4,196.75)=$ 94.84, $p<.001)$. There was not a significant main effect of age group $(p=.048)$. The main effects of emotion was qualified by a significant interaction between age group and emotion,

\footnotetext{
${ }^{12}$ All patterns and significance of findings remained the same when controlling for positive and negative affect at baseline.

13 The main effect of age was not significant when controlling for baseline affect.
} 
$F(4,196.75)=4.00, p=.02$. Simple main effects analyses showed that younger adults $(M=2.20$, $S D=0.13)$ reported a significantly greater neutral state than older adults $(M=1.64, S D=0.12)$. There were no other differences in emotional intensity $(p \mathrm{~s}>.05) .{ }^{14}$

${ }^{14}$ All patterns and significance of findings remained the same when controlling for positive and negative affect at baseline. 